\title{
Reduced neuronal activity and reactivation in Alzheimer's disease
}

\author{
D.F. Swaab ${ }^{1, *}$, P.J. Lucassen ${ }^{2}$, A. Salehi ${ }^{1}$, E.J.A. Scherder ${ }^{3}$, \\ E.J.W. van Someren ${ }^{1}$ and R.W.H. Verwer ${ }^{1}$ \\ ${ }^{I}$ Netherlands Institute for Brain Research, Amsterdam, The Netherlands \\ ${ }^{2}$ Leiden/Amsterdam Center for Drug Research, Leiden, The Netherlands \\ ${ }^{3}$ Free University, Department of Clinical Psychology, Amsterdam, The Netherlands
}

\begin{abstract}
Alzheimer's disease (AD) is a multifactorial disease in which APOE- $\varepsilon 4$ and age are important risk factors. In addition, various mutations (chapter Van Broeckhoven) and even viral infections such as herpex simplex (Itzhaki et al., 1997) may play a role. $\mathrm{AD}$ is characterized histopathologically by the presence of large numbers of neuritic plaques (NPs) and cytoskeletal changes that are present as pretangles after staining, e.g., by Alz-50 (Van de Nes et al., 1993) or AT8 (Schultz et al., 1996), or as neurofibrillary tangles (NFT) after silver staining. NFT are present in the cell bodies of affected neurons, while the same cytoskeletal changes are called neuropil threads when present outside neuritic plaques (Braak et al., 1986) or dystrophic neurites when they are the neuritic components of neuritic plaques (NPs) (Kowall and Kosik, 1987). Dystrophic neurites or neuropil threads are short, thickened, curly, coiled or sometimes hooked fibres. To a lesser degree, NPs and cytoskeletal changes can also be observed in aged, nondemented control subjects.
\end{abstract}

\footnotetext{
*Corresponding author. Netherlands Institute for Brain Research, Meibergdreef 33, 1105 AZ Amsterdam, The Netherlands; Tel.: (31) 20 5665500; fax: (31) 20 6961006. e-mail: t.eikelboom@nih.knaw.nl
}

\section{Alzheimer's disease; what it is not}

It is a well-accepted fact now that AD is not restricted to the cholinergic system, but involves all types of transmitter systems, i.e. also amines, aminoacids and peptides. It is also well-known that the Alzheimer pathology is not restricted to the cortex and hippocampus, but also affects subcortical regions (Braak and Braak, 1995; see chapter Braak). In addition, the neuropathological changes cannot be distinguished qualitatively from those appearing in elderly non-demented subjects. $\mathrm{AD}$ is not a monocausal disease, except for some relatively rare familiar cases, but a multicausal disorder with age as the most important risk factor.

This review will provide evidence in favor of the hypotheses that (i) the neuropathological Alzheimer changes cannot all be explained by a cascade starting with amyloid ( $\beta / \mathrm{A} 4)$ deposits as suggested e.g. by Selkoe (1994), but that (ii) the neuropathological hallmarks of Alzheimer's disease are basically independent phenomena, and that (iii) cell death in Alzheimer's disease is not a major generally occurring phenomenon, but is restricted to a few brain areas. A long struggle has been going on about the question what is more impor- 
tant for the development of dementia: cytoskeletal changes or amyloid. The answer is probably neither. As will be argued in this review, (iv) reduced neuronal activity is most probably one of the major characteristics of AD and may underlie the clinical symptoms of dementia. Experiments will be discussed that indicate that it is attractive to direct therapeutic strategies towards restimulation of neuronal metabolism and repair mechanisms in order to improve cognitive and behavioral symptoms of AD.

\section{Amyloid: just one of the many risk factors involved}

The amyloid cascade hypothesis, as advocated by e.g., Selkoe (1994) and Hardy (1997), constitutes a major, but controversial, working hypothesis in current AD research (Neve and Robakis, 1998). Amorphous plaque deposition is thought to be the primary event. The congophilic components of NPs are assumed to arise from the congo negative amorphous plaques by aggregation of $\beta / \mathrm{A} 4$-protein fibrils. The neurotoxicity of $\beta / \mathrm{A} 4$ would induce NP formation, the occurrence of neuropil threads and dystrophic neurites, followed by NFT formation and, ultimately, cell death. The toxic potency of amorphous plaque deposits is attributed to the $\beta /$ A4-protein (Masters et al., 1985), that consists of 40-43 amino acids and is cleaved from the much larger amyloid precursor protein (APP) (Kang et al., 1987). Grafting genetically transformed cells that overexpress $\beta / \mathrm{A} 4$ amyloid into the suprachiasmatic nucleus of adult rats indeed caused a disruption of circadian rhythms, which is in support of the idea that this compound is neurotoxic (Tate et al., 1992; Kowall et al., 1992; Yankner, 1992). Moreover, AD is linked to trisomy of chromosome 21 (Down's syndrome). In some rare familial Alzheimer cases the disease is due to a point mutation in the APP gene on chromosome 21 (chapter Van Broeckhoven). Although these are certainly arguments in favor of Selkoe's cascade hypothesis, there are also data from a large number of papers that do not fit into this hypothesis (for reviews see Van de Nes et al., 1994; Neve and Robakis, 1998). The vast majority of AD cases $(99.5 \%)$ is not linked to APP gene mutations or an extra copy of chromosome 21 (Rossor, 1993). The occurrence of familial AD cases linked to chromosomes other than chromosome 21, e.g. chromosome 14 (Mullan et al., 1992; Schellenberg et al., 1992; St. George-Hyslop et al. 1992; Van Broeckhoven et al., 1992), chromosome 12 (Blacker et al., 1998) or 1 (Levy-Lahad et al., 1995) as well as the cases linked to the APOE- $\varepsilon 4$ locus on chromosome 19 (Pericak-Vance et al., 1991; Strittmatter et al., 1993a,b; Small et al., 1995; Reiman et al., 1996) are not directly linked to the amyloid cascade hypothesis. Moreover, in the superior temporal sulcus, the amyloid burden is not related to neuronal loss, number of NFTs or duration of the disease (Gómez-Isla et al., 1997), and in transgenic mice with APP expression amyloid did not appear to be acutely neurotoxic (Irizarry et al., 1997). Amyloid accumulation is thus perhaps best considered as just one of the many risk factors involved in AD.

\section{Cytoskeletal changes without neuritic plaques}

The histopathological changes in the punch-drunk demential syndrome of boxers (dementia pugilistica) do not agree with the amyloid cascade hypothesis either. The hippocampus and cortex of AD-demented boxers contain many amorphous plaques, NFTs and neuropil threads, but very few, if any, NPs (Roberts et al., 1990). In addition, in several cases of familial and non-familial Alzheimer patients NFTs have been found without amyloid deposition (Bouras et al., 1994; Bird et al., 1989; Sumi et al., 1992). The hypothalamic nucleus tuberalis lateralis (NTL) shows strong cytoskeletal alterations in AD, as appears from the intense staining of NTL neurons and neuropil threads by the antibodies Alz-50, tau-1 and 3-39 (Swaab et al., 1992; Van de Nes et al., 1993). These are pretangle changes, since silver-stained NPs are rare in the NTL (Kremer et al., 1991; Kremer, 1992; Fig. 1). In addition, clusters of NPs and tangles are spatially not related (Armstrong et al., 1993). These observations indicate that cytoskeletal changes may in principle occur independently of aggregated $\beta / \mathrm{A} 4$ fibril amyloid cores. 
No transformation of amorphous to neuritic plaques $(N P S)$

It is presumed by many authors that there is a transformation from amorphous plaques to NPs, but the relationship between these two types of AD changes is equivocal both in histopathological and biochemical terms. Amorphous plaques do not seem to be neurotoxic or to induce NFTs. Cytoskeletal changes and amorphous plaques are not related in their localization. Amorphous plaques are present in the cerebellum of AD and Down syndrome patients without the presence of neurofibrillary changes in that brain area (Braak et al., 1989a; Joachim et al., 1989). In addition, a widespread presence of amorphous plaques is not necessarily associated with AD dementia. The percentage of elderly, non-demented subjects over the age of 75 years with $\beta / \mathrm{A} 4$ deposits in the cortex may reach $80 \%$ (Davies et al., 1988), whereas for the parahippocampal and superior temporal gyri of non-demented centenarians this proportion may even approximate 100\% (DeLaere et al., 1993). In the hippocampus and neocortex of elderly, non-demented control subjects, large amounts of amorphous plaques may be present, while NFTs are practically absent (Duyckaerts et al., 1988; Barcikowska et al., 1989; DeLaere et al., 1990), and the amount of neuropil threads is low (Dickson et al., 1988; McKee et al., 1991). In addition, large amounts of amorphous plaques may also be found with hardly any neurofibrillary changes in the parvocellular layer of the presubiculum (Kalus et al., 1989; Akiyama et al., 1990). Also, Bouras et al. (1994) found that the extent of amyloid deposition in the hippocampal area was not correlated with the diagnosis Alzheimer's disease.

Amorphous plaque deposition in the brain is rather diffuse, whereas NPs are concentrated in particular areas. Amorphous plaques are found in all six neocortical layers (Braak et al., 1989b; Arnold et al., 1991), whereas NPs are mainly found in layers II-III (Pearson et al., 1985; Rogers and Morrison, 1985 Duyckaerts et al., 1986). Furthermore, apart from the fact that amorphous plaques occur in a large proportion of the non-demented elderly, they are also found in neurodegenerative disorders other than AD, e.g. progressive supranuclear palsy, Parkinson's disease, Huntington's chorea and frontal lobe dementia. However, in these disorders amorphous plaques are not associated with the presence of NPs or neuropil threads as they are in AD (Mann and Jones, 1990).

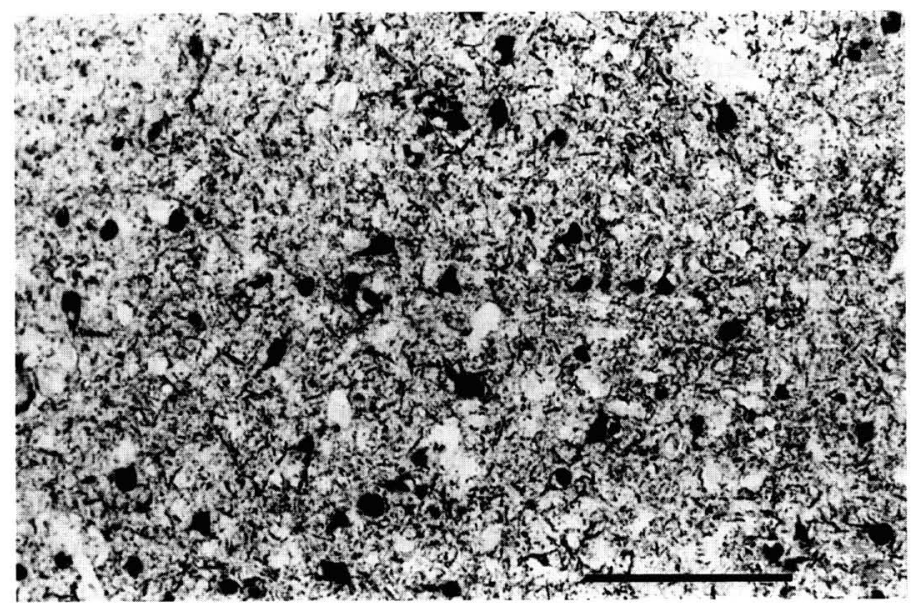

Fig. 1. The nucleus tuberalis lateralis in a female Alzheimer patient, 64 years of age, stained with Alz-50. Note the extremely dense network of dystrophic neurites and positive cell bodies ( $\mathrm{Bar}=200 \mu \mathrm{m})$. Neuritic or amorphous plaques are hardly found in this nucleus and therefore the pretangles as stained by Alz-50 seem to be formed independently of amyloid deposits. 
The transformation from amorphous plaques into NPs can also be questioned on the basis of the finding that amorphous plaques stain with antibodies raised against the $\beta / \mathrm{A} 4$-protein and the APP N-terminus, but not with antisera raised against the APP carboxy-terminal region, whereas classical NPs stain with all three antisera (Tagliavini et al., 1991). These observations indicate that there may also be differences in the chemical composition of NPs and amorphous plaques, in addition to a difference in the aggregated versus the nonaggregated state of the $\beta / \mathrm{A} 4$-protein fibrils. The most important argument against a transformation is, however, that plaques that should represent intermediate forms between amyloid plaques and NPs have never been reported.

\section{Neuritic plaques and neurofibrillary tangles may occur independently}

The NPs with a congophilic amyloid core, in particular, have attracted attention, since amyloid has a central place in the cascade hypothesis. However, it is not so much the NPs but rather the cytoskeletal changes that correlate with duration and severity of AD (Arriagada et al., 1992; Braak and Braak, 1991; McKee et al., 1991; MukaetovaLadinska et al., 1993). NFTs are often proposed to have their starting point in the neurotoxicity of NPs. This idea is supported by the observation that many classical NPs are present in the "terminal zone of the perforant pathway", which corresponds to the outer two-thirds of the molecular layer of the dentate gyrus and to the distal dendrites of the CAl zone (Hyman et al., 1986). The neurons of the perforant pathway projections that originate from the entorhinal cortex in fact contain many NFTs in AD (Hyman et al., 1986). However, the idea that the formation of NFTs in entorhinal cortex neurons and the formation of NPs in the hippocampal CA1 region are necessarily linked, was not supported by statistical analysis. The correlation between the density of cellular NFTs in the entorhinal cortex neurons and classical NPs in the dentate gyrus and CA1 region as projection area appeared to be weak (Armstrong et al., 1992). In addition, clusters of NPs and tangles are spatially not related (Armstrong et al., 1993). Moreover, 30\% of the demented senile "Alzheimer patients" with plaques in the neocortex appeared to lack tangles in this brain area (Terry et al., 1987). Similar discrepancies are found in the striatum, where AD-affected type IV and $\mathrm{V}$ interneurons in the caudate nucleus and putamen develop NFTs and dystrophic neurites, while hardly any classical NPs are found (Braak and Braak, 1990). This indicates that NFT formation in the striatum is a local pathology not induced by classical NP deposition in this structure. In the superior temporal sulcus no relationship was found between the amount of amyloid and neurofibrillary tangles (Gómez-Isla et al., 1997). These observations suggest that the occurrence of classical NPs on the one hand and NFT formation on the other are phenomena that occur independently of each other.

Although it has been presumed that amyloid may be retrogradely transported and then act toxically on cell bodies, there is no precise relationship between the clustering of NPs in the neocortex, and the localization of the terminals of the magnocellular cholinergic neurons of the basal forebrain or noradrenergic cells in the locus coeruleus that contain NFTs. In the neocortex, NPs predominantly occur in layers II-III (Pearson et al., 1985; Rogers and Morrison, 1985; Duyckaerts et al., 1986), whereas cholinesterase histochemistry reveals the most dense staining in layers I and VI (Mesulam et al., 1983), which are the layers that have the fewest NPs. This means that the layers to which the magnocellular cells of the nucleus basalis of Meynert (NBM) project do not coincide with the layers with the densest NP concentration. Dopamine- $\beta$-hydroxylase histochemistry has made it clear that also the locus coeruleus neurons send their axons mainly to layers I and VI (Morrison et al., 1982). This means that also the neocortical layers to which locus coeruleus neurons send their axons do not correspond with the neocortical layers that show a concentration of NPs either, i.e. layers II and III. Apparently, NFT formation in the cholinergic 
neurons of the NBM and the noradrenergic cells of the locus coeruleus does not seem to be directly related to the pattern of highest NP deposition in the neocortical layers.

Another histopathological argument that suggests that cytoskeletal changes are not necessarily locally induced by aggregated $\beta / \mathrm{A} 4$-protein fibrils is provided by our observations in the hypothalamus. Firstly, congophilic plaques in the hypothalamus are rare (Standaert et al., 1991). However, various hypothalamic nuclei appear to be affected by Alz-50 stainable "pretangle" cytoskeletal changes (Swaab et al., 1992; Van de Nes et al., 1993). In addition, the hypothalamic nucleus tuberalis lateralis (NTL) hardly undergoes any amorphous or NP formation in AD (Kremer et al., 1991), although the nucleus stains very intensively with Alz-50 (Kremer et al., 1991; 1992; Swaab et al., 1992; Van de Nes et al., 1993; Fig. 1). The hypothalamic suprachiasmatic nucleus, too, may show some Alz-50-stained cell bodies and altered fibres in AD, while amorphous or classical plaques have never been observed in this nucleus (Swaab et al., 1992; Van de Nes et al., 1993; Van de Nes et al., 1998).

These observations suggest that this sequence of events, i.e., pretangles, neuropil threads and NFTs by neurotoxic NPs does not always take place, nor does it seem to play such a crucial role in the pathogenesis of $\mathrm{AD}$, as proposed on the basis of the amyloid cascade hypothesis. Rather, NP formation has to be seen as an independent process. This would also explain why no spatial relationship is seen between the distribution of neuropil threads and NPs. In addition, it would clarify why in the neocortex of nondemented elderly patients large amounts of NPs can be found, whereas neuropil threads (Dickson et al., 1988; McKee et al., 1991) or NFTs are virtually absent (Katzman et al., 1987; Crystal et al., 1988; Arriagada et al., 1992).

\section{Cytoskeletal changes and NPs do not induce cell death}

The last step of the amyloid cascade hypothesis consists of the idea that neurons that show cytoskeletal changes are indicative of impending neuronal death and that the process of cell death would be induced by the neurotoxic NPs.

The findings in the locus coeruleus in AD are in agreement with this last part of the cascade theory. Large neuromelanin pigment-containing neurons in this structure develop NFTs, and neuronal death in AD may be the fate of up to $80 \%$ of these neurons (Bondareff et al., 1982; Chan-Palay and Asan, 1989; German et al., 1992; Hoogendijk et al., 1995). The proposed sequence, i.e. that NFT formation is followed by dramatic cell loss, was thought to be common in AD. However, this sequence of events only seems to hold for a limited number of brain areas (e.g. locus coeruleus, superior temporal sulcus and CA1 of the hippocampus). Cell loss is indeed considerable in the latter structure in AD (West et al., 1994). In the superior temporal sulcus $50 \%$ of the neurons are lost, but it should be mentioned that no relationship was found with the number of NPs or NFTs (Gómez-Isla et al., 1997). Cell loss is not present in large amounts in the nucleus basalis of Meynert (NBM), in spite of the fact that in early reports neuronal loss of up to $90 \%$ was also reported (Mann et al., 1984; Whitehouse et al., 1982), only a small part of which was considered to be related to aging (Lowes-Hummel et al., 1989; De Lacalle et al., 1991). Following careful morphometric analysis, the earlier reported loss in the large-sized cholinergic neurons in the NBM in AD could, however, be explained by cell shrinkage, reduced activity, and loss of cholinergic cell markers rather than by cell loss (Rinne et al., 1987; Allen et al., 1988; Salehi et al., 1994; Vogels et al., 1990; Fig. 2). Regeur et al. (1994), using unbiased sampling and counting methods, showed that in spite of the often observed cortical atrophy in $\mathrm{AD}$, global neocortical cell loss does not take place in this brain area of AD patients, providing strong evidence that neuronal shrinkage rather than cell death is a major phenomenon in this neurodegenerative disorder (Fig. 3). Nor do data on Alz-50stained pretangle changes and neuronal cell counts of the sexually dimorphic nucleus (SDN) and nucleus tuberalis lateralis (NTL) in control and 

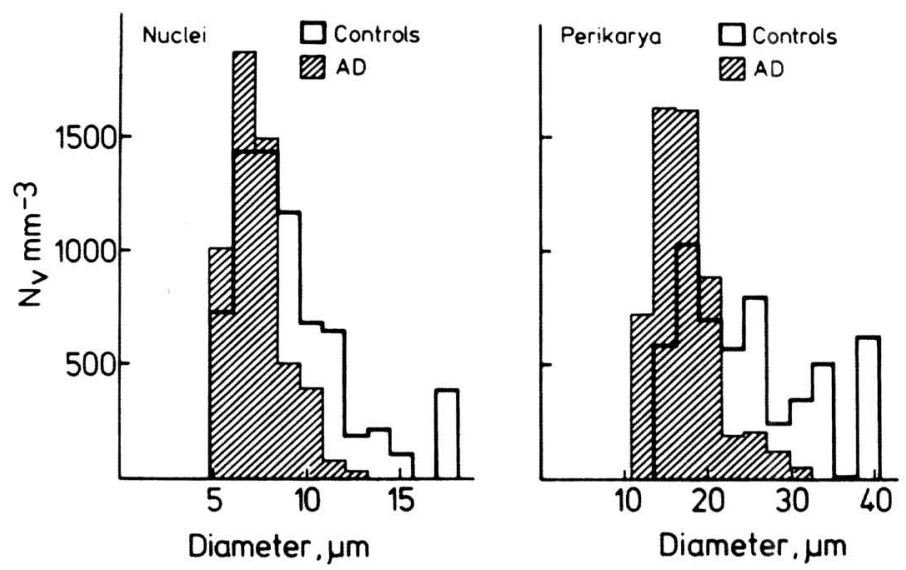

Fig. 2. Size-specific numerical densities (Nv) of neuronal nuclei and perikarya in non-demented controls and AD patients in the nucleus basalis of Meynert (NBM) (from Rinne et al., 1987, with permission). Note that the number of large neurons decreases, while the number of small neurons increases, which illustrates neuronal shrinkage in the NBM.

AD hypothalami of different ages support the idea that pretangle staining is indicative of impending cell death. Alz-50-stained cell bodies and dystrophic neurites in the SDN have only been observed in AD and not in controls (Swaab et al., 1992; Van de Nes et al., 1993), whereas the pattern of loss of SDN neurons in AD is similar to that during normal aging (Swaab and Hofman, 1988). In addition, the Alz-50 staining of the NTL of AD patients is so abundant (Fig. 1) that it can even be seen with the unaided eye, although neuron number in $\mathrm{AD}$ is not different from that in control subjects (Kremer et al., 1991; Kremer, 1992).

The CA1 area of the hippocampus is one of the few areas that show a very clear neuronal loss in AD. West et al. (1994) have shown that the number of neurons in the CAl area of the hippocampus is much more reduced in $\mathrm{AD}$ than in normal aging. Since this area shows a massive number of NFTs and NPs in AD, we chose CAl to study the question whether or not NPs may induce local cell death (Emre et al., 1992; Kowall et al., 1992). Our study (Salehi et al., 1996a) showed that there is indeed a slightly lower neuronal density around NPs. In addition, we found a negative relationship between the size of the neuritic plaques and neuronal density around them, indicating that the neurotoxic effect is, apparently, dose-dependent. However, it should be noted that

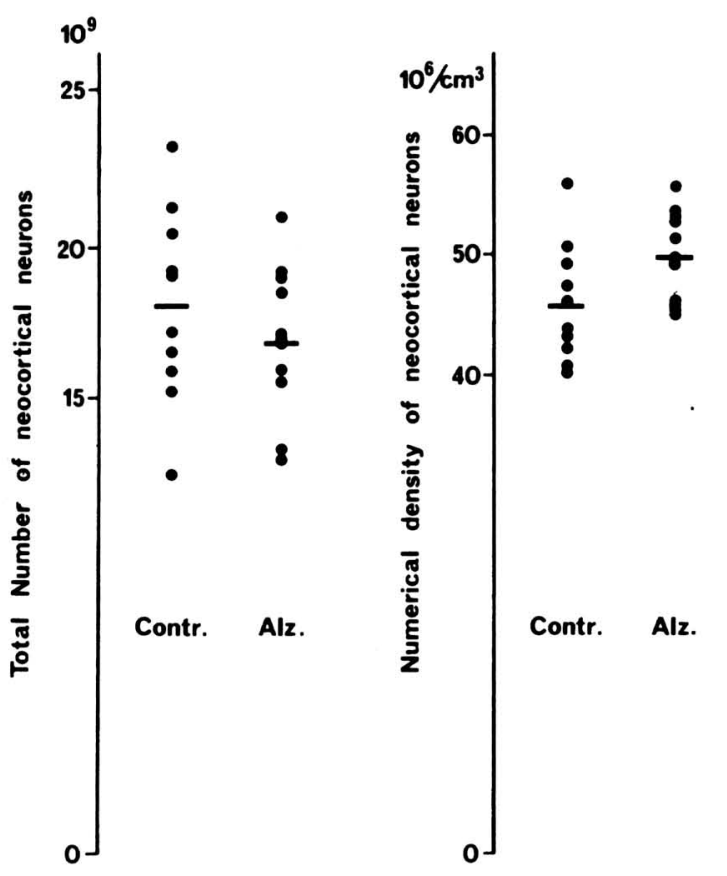

Fig. 3. Total number of neocortical neuron number in $11 \mathrm{AD}$ patients and 10 matched controls (from Regeur et al., 1994, with permission). Note that there is no significant decrease in neuron number in the AD patients, excluding massive neuronal death as a major phenomenon in the cortex of Alzheimer patients.

the contribution of this effect on the total cell death in the CA1 area was very limited, i.e. $2.6 \%$ 
out of the reported $70 \%$ cell death. This study therefore again supports the notion that the occurrence of NPs and cell death are largely two independent phenomena.

The fact that the various neuropathological hallmarks apparently occur, in principle, independent of each other, explains the regional variability. in the microscopy of AD much better than the amyloid cascade theory. In the differential regional distribution of AD changes (Braak and Braak, 1995; Price et al., 1991; see chapter Braak) the activity stage of the local neurons also seems to be a factor of major importance (see below).

\section{No animal models for $A D$}

Based on the presence of mutations in the APP gene in some familial AD forms and in early-onset AD dementia in Down syndrome patients, presumably related to overproduction of normal APP, various transgenic mouse models overexpressing APP have been developed and tested. However, the results obtained thus far are rather disappointing (for methodological considerations see Yankner, 1992). A major step forward was claimed by Kawabata et al. (1991), who reported the detection of amyloid deposits and NFTs in the transgenic mouse brain. However, the authors had to retract their paper because they could not reproduce the histopathological AD changes. Another research group reported the presence of small deposits of age-related $\beta / \mathrm{A} 4$-protein-like immunoreactivity in the mouse hippocampus (Wirak et al., 1991). These deposits, however, appeared to be clusters of intracytoplasmic inclusions in astrocytic processes, i.e., a murine corpora amylacea-like structure that can exhibit nonspecific staining with a variety of polyclonals (Jucker et al., 1992). Other transgenic mice models with an overproduction of normal APP revealed some $\beta / \mathrm{A} 4$-amyloid-like deposits in the hippocampus and cortex, but significant behavioral changes or histopathological changes associated with AD were not found (Quon et al., 1991; Kammesheidt et al., 1992; Andrä et al., 1996; Games et al., 1995; Malherbe et al., 1996). The best animal models give some 10 -fold increase in the level of APP, but even these mice did not show silver staining NFTs (Hsiao et al., 1996; Games et al., 1995; Masliah et al., 1996; Greenberg et al., 1996; Irizarry et al., 1997; Sturchler-Pierrat et al., 1997; Holcomb et al., 1998) (see chapters by Hsiao and Chen). In addition, human neurons that secrete $\mathrm{A} \beta$ did not induce Alzheimer pathology following transplantation into rodent brain (Mantione et al., 1995). Thus, so far, no animal model has yet been developed that can fully support the amyloid cascade hypothesis.

\section{Neuronal metabolic rate and neurodegeneration}

Regarding the role of neuronal metabolic activity in degeneration during brain aging and $\mathrm{AD}$, two basic, opposite concepts were formulated and extensively discussed some years ago (Swaab, 1991). The peer review on the "use it or lose it" hypothesis, which has, as far as the brain is concerned, been proposed to be a good alternative for the previously generally accepted "wear and tear" hypothesis of senescence, evoked a debate that elaborated on existing dogmas, e.g. from Rosen (1961), and Pitt (1993). The present chapter reviews some recent literature in relation to the idea that activated neurons can better resist aging and AD, paraphrased by us as "use it or lose it".

The "wear and tear" concept is based on the assumption that during normal metabolic functioning of postmitotic cells, damaging factors such as oxygen radicals are continuously being generated which induce insults, some of which irreversible, in various cellular components such as proteins or the genome (Gensler and Bernstein, 1981; Benzi and Moretti, 1995). According to the "wear and tear" hypothesis, this damage would accumulate with age and cause progressive malfunctioning and, ultimately, the death of the cell. Well known examples that support this concept are e.g. studies on flies that revealed an inverse relationship between life-span and metabolic rate. Life-span could be prolonged considerably by reducing the level of physical activity and thus the metabolic rate of these flies (Orr and Sohal, 
1994). This effect of physical activity was indeed related to enhanced oxidative DNA damage levels as measured in homogenates of these insects (Agarwal and Sohal, 1994; Orr and Sohal, 1994), suggesting that oxidative damage as a consequence of physical activity is a major causal factor in physical aging. A similar suggestion comes from the observations that rats on a restricted feeding schedule (Masoro et al., 1982; McCarter et al., 1985) and hibernating animals (Lyman et al., 1981) live longer. However, the mechanism of action of these effects is far from clear. In addition, courtship, which also increases physical activity, reduces the longevity of male Drosophila melanogaster (Cordts and Partridge, 1996). However, in the human brain we did not see any increase in oxidative DNA damage in the frontal, occipital, or temporal cortex, nor did we notice an increase in hippocampal tissue in AD (Te Koppele et al., 1996) although this was expected on the basis of the proposed accumulation of DNA damage. For the brain, increased metabolism seems to be protective rather than damaging. The finding that the supraoptic nucleus (SON), a very stable and metabolically highly active group of hypothalamic neurons, becomes even activated with aging (see below and Fig. 5), and the observation in the NBM, that is severely affected in AD also shows a strong decrease in neuronal activity (see below; Figs. 2,6), are in favour of the "use it or lose it" concept (Swaab, 1991).

The "use it or lose it" principle might also apply to other neurodegenerative diseases, as indicated by a study by Kish et al. (1992) who found a negative correlation between dopamine loss during aging and neuronal activity. A significant decline was present in striatal dopamine levels with increasing age. The level of dopamine metabolism in different parts of the striatum, however, as measured by the homovanillic acid/dopamine ratio, was found to be inversely related to the degree of dopamine loss. This suggests that striatal subdivisions with a physiologically higher dopamine metabolism run less risk of suffering dopamine loss with advancing age. Similar relationships have been reported for nonhuman primates treat- ed with the neurotoxin MPTP, in which the most severe dopamine loss was found in subdivisions of the striatum with the lowest dopamine turnover rates (Elsworth et al., 1989). These data do not tally with the oxydative damage hypothesis of aging (Harman, 1994; Ames et al., 1989) and support the "use it or lose it" concept.

In addition, affirmative data for the "use it or lose it" hypothesis come from the biological clock of the brain or suprachiasmatic nucleus (SCN), which plays a central role in circadian rhythm generation and which is sensitive to input from the environmental light cycle. Degenerative changes have been described in circadian rhythm generation in old age (see below) as well as decreases in the number of vasopressin (AVP)- and vasoactiveintestinal-polypeptide (VIP)-expressing neurons in the SCN of old people and Alzheimer patients. It was shown that age-related decreases in rhythm amplitudes could be restored after stimulating the SCN of old animals by housing them under high light conditions (Witting et al., 1993). The very same light settings were also able to prevent the age-related decrease in AVP-neurons in the SCN of old animals (Lucassen et al., 1995; Fig. 4). This shows that considerable plasticity is still present in the SCN of old rats, both in functional as well as in anatomical terms, that is sensitive to stimulation by means of an increased input. Interestingly, similar positive effects of light therapy have been reported in clinical studies with Alzheimer patients (see below).

Additional support for the important role of the activity-related energy metabolism for neuronal survival comes from animal experimental studies on the hippocampus. Chronically elevated levels of corticosterone were shown in rat to endanger cellular survival and to enhance the aging process in the hippocampus (Sapolsky et al., 1986; Landfield and Eldridge, 1991). As a possible explanation, it was proposed that glucocorticoids would inhibit glucose uptake into hippocampal neurons, leading to diminished energy stores. This energy impairment would then result in decreased highenergy phosphate stores and a deteriorating membrane potential. These conditions reduce the 


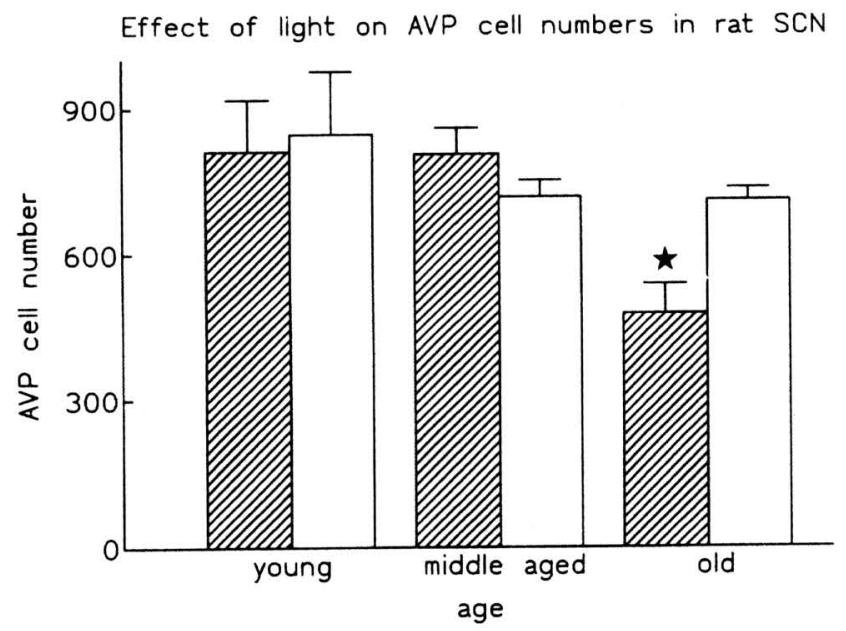

Fig. 4. Graph depicting numbers of vasopressin (AVP) expressing neurons in the suprachiasmatic nucleus (SCN) of rats of different ages after housing under low (hatched bars) or high (white bars) light intensity. Bars represent mean \pm SEM. ${ }^{*}=p<0.05$ compared with both young and middle-aged animals under low light intensity. The numbers of AVP expressing neurons in the old group after bright light treatment no longer differ significantly from the young and middle-aged animals. Light seems thus to stimulate the neurons of the SCN in the old age group and to prevent their loss of AVP expression (from Lucassen et al., 1995, with permission).

voltage sensitive $\mathrm{Mg}^{2+}$-block of NMDA receptors, allowing these receptors to be overactivated by relatively low, endogenous concentrations of glutamate (Beal et al., 1992a,b; Armanini et al., 1990). These observations suggest that energyimpaired less active cells may become increasingly vulnerable to endogenous concentrations of excitatory aminoacids. Denervation of hippocampal neurons can be considered as another way of inactivation of cell groups. After combined dopaminergic and cholinergic denervation of the hippocampus, granule cells of the rat dentate gyrus displayed abnormally phosphorylated tau, in particular in the apical dendrites (Torack and Miller, 1995), which supports the idea that inactivation and the occurrence of degenerative changes are coupled.

On the other hand, activation of, e.g, the hippocampus seems to be coupled to regenerative changes and plasticity. By means of chronic housing of juvenile or adult rats in an enriched environment, spatial learning in the Morris water maze could be facilitated, which was found to be associated with increased hippocampal nervegrowth factor (NGF) levels (Falkenberg et al.,
1992). Also, increased expression of the NGFinduced immediate early gene NGF1-A and of brain-derived neurotrophic factor (BDNF) in the hippocampus was found after environmental enrichment (Falkenberg et al., 1992; Olsson et al., 1994; Wallace, 1995). Black et al. (1991) also showed that interaction with the environment is associated with neural plasticity, since enriched environment housing conditions induced an improved cerebral vasculature and an increased number of mitochondria in the rat visual cortex, necessary for increased metabolic demands. In other animal studies, neural plasticity changes such as dendritic growth could be demonstrated as early as after 4 days of housing of young animals in a complex environment (Wallace 1992). In particular early experience with a complex environment has been suggested to create a "neural reserve" that may interfere with neuronal degeneration during aging. Following enriched environment housing conditions, neural plasticity was induced even in old animals in which small increases in cortical thickness were measured (Van Gool et al., 1987). These observations suggest the presence of a relation between growth 
factor expression and neuronal stimulation that may contribute to an explanation of at least some of the beneficial effects on survival in activated cells (Swaab, 1991a).

\section{Decreased neuronal activity is a major hallmark of Alzheimer's disease}

Various observations indicate that decreased neuronal activity is an essential characteristic of $\mathrm{AD}$, either as a risk factor or as a direct pathogenetic factor (Beal, 1994) and that high or enhanced neuronal activity would protect against the degenerative changes of aging of $\mathrm{AD}$, an hypothesis paraphrased as "use it or lose it" (Swaab, 1991). In $\mathrm{AD}$ a marked reduction of regional cerebral blood flow and cerebral hemoglobulin oxygenation may occur during activation of brain function (Hock et al., 1997). There is indeed considerable support in the literature for the view that decreased metabolic rate is a major and early hallmark of AD. It has been reported that the AD brain shows a lower total amount of protein (Suzuki et al., 1965), a clear reduction in total cytoplasmic RNA (Bowen et al., 1977; Mann et al., 1981; Doebler et al., 1988) and messenger RNA (Sajdel-Sulkowska and Marotta, 1984; Guillemette et al., 1986; Taylor et al., 1986), reduced glucose metabolism, especially in temporal and parietal lobes, as shown by positron emission tomography (PET) (Hoyer et al., 1988; Kumar et al., 1993; Meneilly and Hill 1993; Meier-Ruge et al., 1994; Swerdlow et al., 1994), a smaller cell size, such as the somatostatin neurons in the cortex (Joynt and McNeill, 1984) and a small size of the neuronal Golgi apparatus that is indicative of decreased metabolic activity in AD (Salehi et al., 1994; 1995b,c). The changes in regional cerebral glucose metabolism as measured by PET in the tempoparietal frontal and occipital cortex, were correlated with a change of the Mini Mental State Examination score in probable Alzheimer patients, suggesting that clinical deterioration and metabolic impairment are closely related (Mielke et al., 1994). In addition, a significant negative relationship between metabolism and the density of plaques was found in $\mathrm{AD}$
(Mielke et al., 1996). The activity of cytochrome oxidase (CO), which constitutes the terminal enzyme (complex IV) of the mitochondrial enzyme transport chain, was reduced in the frontal, temporal and parietal cortex and hippocampus of AD patients (Chandrasekaran et al., 1994; Kish et al., 1992a; Chagnon et al., 1995; Simonian and Hyman, 1993; 1994; Verwer et al., 1998). In addition, mRNA coding for subunit II was severely decreased in the hippocampus of Alzheimer patients (Simonian and Hyman, 1994). Since CO activity is tightly coupled with neuronal activity (Wong-Riley, 1989), the reduction in its activity in AD may possibly be explained by neuronal hypofunction or mitochondrial loss. The deficiency of this key energy enzyme also points to the occurrence of an hypometabolic process in aging and AD (Chandrasekaran et al., 1994; Kish et al., 1992a). The possible importance of $\mathrm{CO}$ deficiency for the development of $\mathrm{AD}$ was reinforced by a study on platelets that showed that mutations in mitochondrial genes for $\mathrm{CO}$ subunits segregate with late-onset AD (Davis et al., 1997). However, a more recent study on brain tissue could not confirm that study, and concluded that mitochondrial DNA mutations may have only contributed to the onset of the disease in one patient with an APP mutation (Hutchin et al., 1997).

Measuring the cerebral metabolic rate (CMR) in healthy and demented subjects, $19 \%$ to $40 \%$ reductions in the CMR of glucose, but not of oxygen, were found in mild to severe AD patients (Hoyer, 1992; 1995b). These changes have been suggested to relate to brain insulin action, or brain insulin receptor function (Hoyer et al., 1991; Hoyer, 1995a; 1995b; Craft et al., 1996). Also, diminished activities of enzymes active in glucose metabolism and ATP formation from other sources than glucose have also been demonstrated in AD (Hoyer, 1992; 1995b). In this respect it is interesting to note that isolated microvessels from the temporal cortices of Alzheimer patients showed decreased glucose metabolism, suggesting a global defect in brain energy metabolism (Marcus et al., 1989). Indeed, a 50\%-70\% decline of 
glucose metabolism is found in the brain of Alzheimer patients, causing the ATP synthesis to be critically lowered (Meier-Ruge et al., 1994). The reduced blood brain barrier and neuronal glucose transporters GLUT-1 and GLUT-3 in Alzheimer patients may play a crucial role in these metabolic changes (Kalaria and Harik, 1989; Mooradian et al., 1997; Simpson et al., 1994).

As to the issue of hypometabolism being an early event, an important observation is that of Foster et al. (1984), who demonstrated that a substantial decrease in cerebral glucose metabolism may precede cognitive impairment. This observation was supported by Small et al. (1995) and Reiman et al. (1996), who found that in late middle-aged, cognitively normal subjects who were homozygous for the APOE- $\epsilon 4$ allele, and thus at risk for $\mathrm{AD}$, have already reduced glucose metabolism in the same region of the brain that is later affected in patients with probable AD. The effect on APOE type is region-specific. APOE- $\epsilon 4$ genotype seems to go together with lower metabolic rate in the tempero parietal region, but with an increased metabolic rate in the frontal region (Higuchi et al., 1997). Reduction of regional cerebral glucose metabolism in later stages of $\mathrm{AD}$ is related to neuropsychological impairment (Haxby et al., 1988; Mielke et al., 1994; Slansky et al., 1995). It is presumed that cortical glucose hypometabolism in AD may reflect reduced synaptic activity (Salmon et al., 1996). These observations support the notion that $\mathrm{AD}$ may primarily be a hypometabolic disorder (Swaab, 1991). It is, moreover, interesting to note that Parkinson patients with dementia show a global decrease in glucose metabolism similar to that in $\mathrm{AD}$, i.e. with more severe abnormalities in the tempero-parietal region (Peppard et al., 1992).

Two major questions concerning the pathogenesis of $\mathrm{AD}$ were therefore (i) whether the presence of plaques or tangles in $\mathrm{AD}$ is indeed related to decreased neuronal activity in various brain areas and, if that is the case (ii) whether these neuropathological AD hallmarks would induce decreased metabolic rate or vice versa, or, alternatively, whether the neuropathological AD changes and decreased metabolic rate would occur independently. Our research supports the latter possibility (see below).

\section{Relationship between Alzheimer neuropathology and decreased metabolism}

Using the size of the Golgi apparatus as a histological parameter of chronic activity changes in neurons, we studied the neuronal activity in areas with different types of neuropathological AD changes. The hypothalamus contains several nuclei which are differentially affected in AD. For instance, the supraoptic nucleus (SON) is generally not affected by AD changes and even shows hyperactivation during aging, both in controls and AD patients (Schultz et al., 1997; Swaab et al., 1992; Lucassen et al., 1994; Fig. 5). This in contrast to the nucleus basalis of Meynert (NBM) that shows clear signs of atrophy (Rinne et al., 1987; Figs. 2, 6), cytoskeletal alterations (Swaab et al., 1992; Van de Nes et al., 1993) and some NP formation (Rudelli et al., 1984). In addition, we studied the CA1 area of the hippocampus, a brain region which is not only affected by cell death (West et al., 1994), but also shows an abundance of NFT and a moderate amount of NPs (Mann et al., 1985). In the hypothalamic and hippocampal tissue from controls and AD patients, different stages of neurofibrillary degeneration were related to neuronal activity by assessing Golgi apparatus size in the following conditions:

\section{Absence of $A D$ changes}

The SON of the hypothalamus appears to be spared in AD. Generally no classical AD neuropathology is present, and even using antibody Alz50 as an indicator of early cytoskeletal alterations (Bancher et al., 1989), no staining of SON neurons is generally found (Swaab et al., 1992; Van de Nes et al., 1993). Only in a small subpopulation of elderly people, neurofibrillary degeneration was observed in the SON and paraventricular nucleus (Schultz et al., 1997). Furthermore, no cell loss is found, either in aging or AD (Goudsmit et al., 


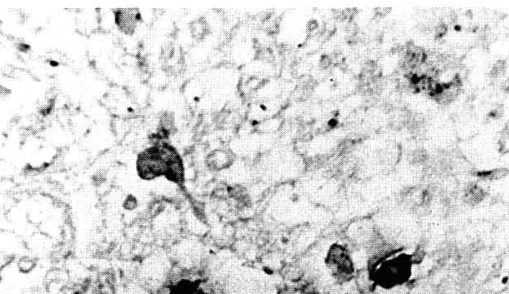

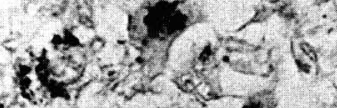

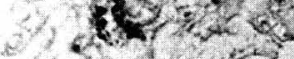

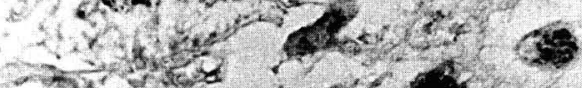
5.

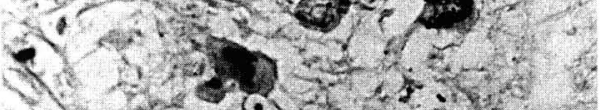

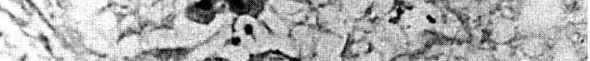
- 5 a

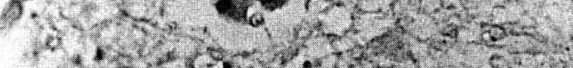

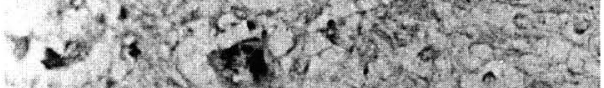

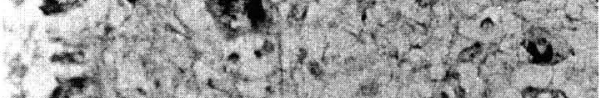
(c)

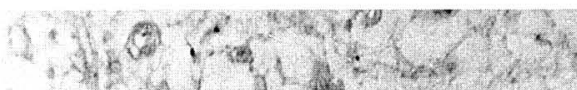

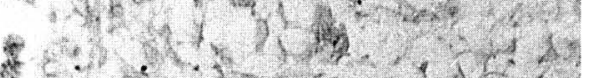

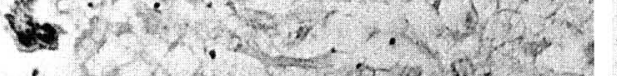

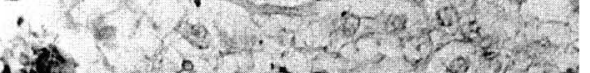

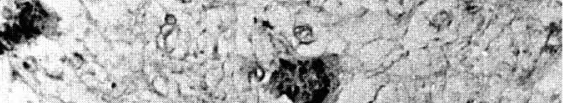

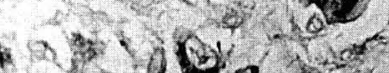

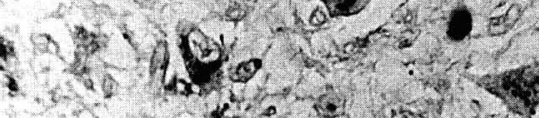

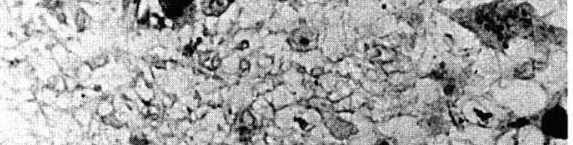

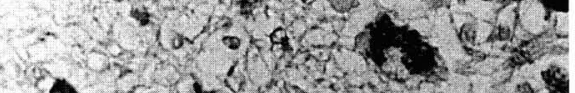

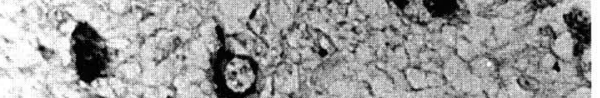

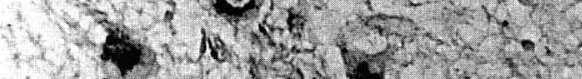

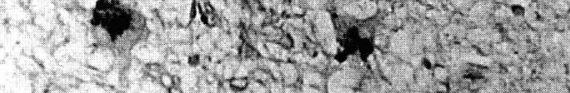

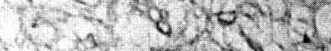

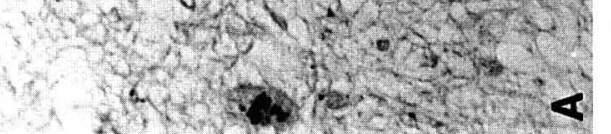

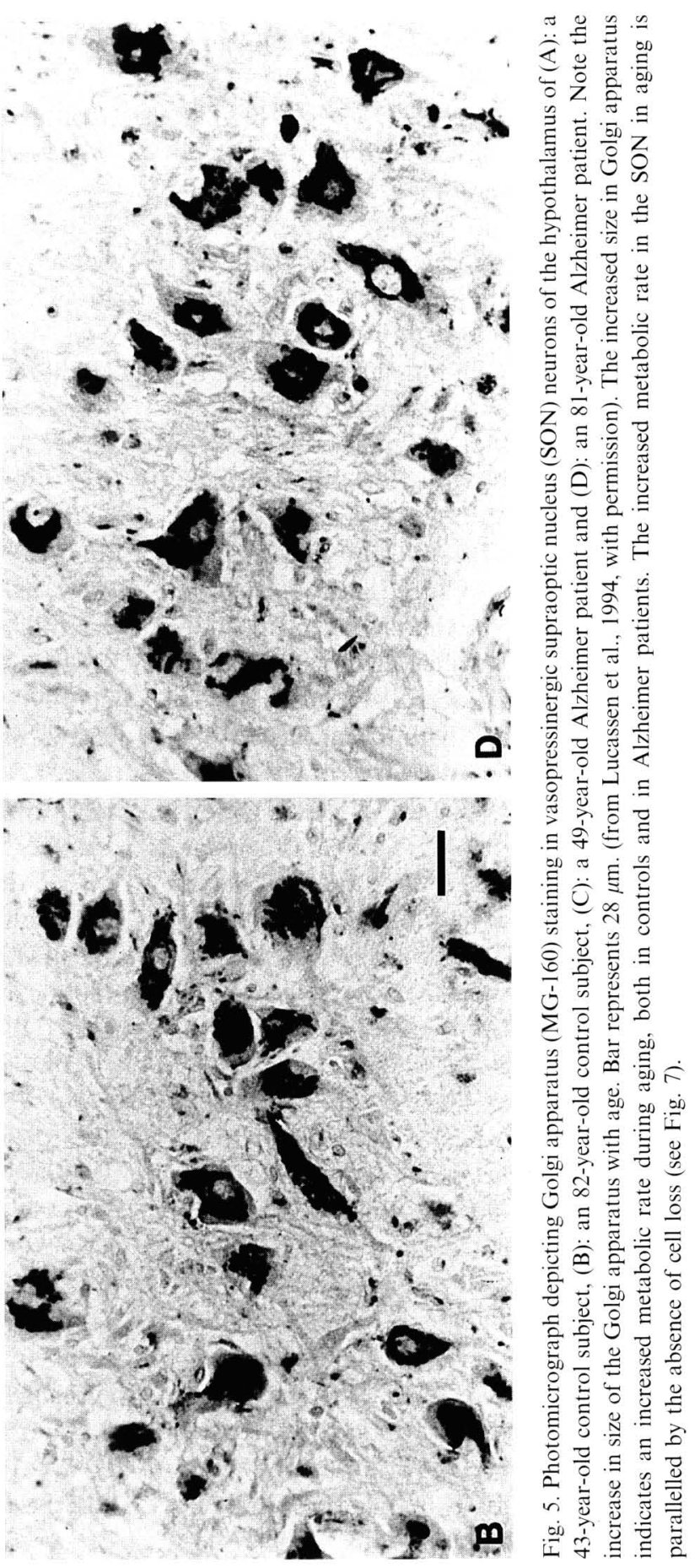



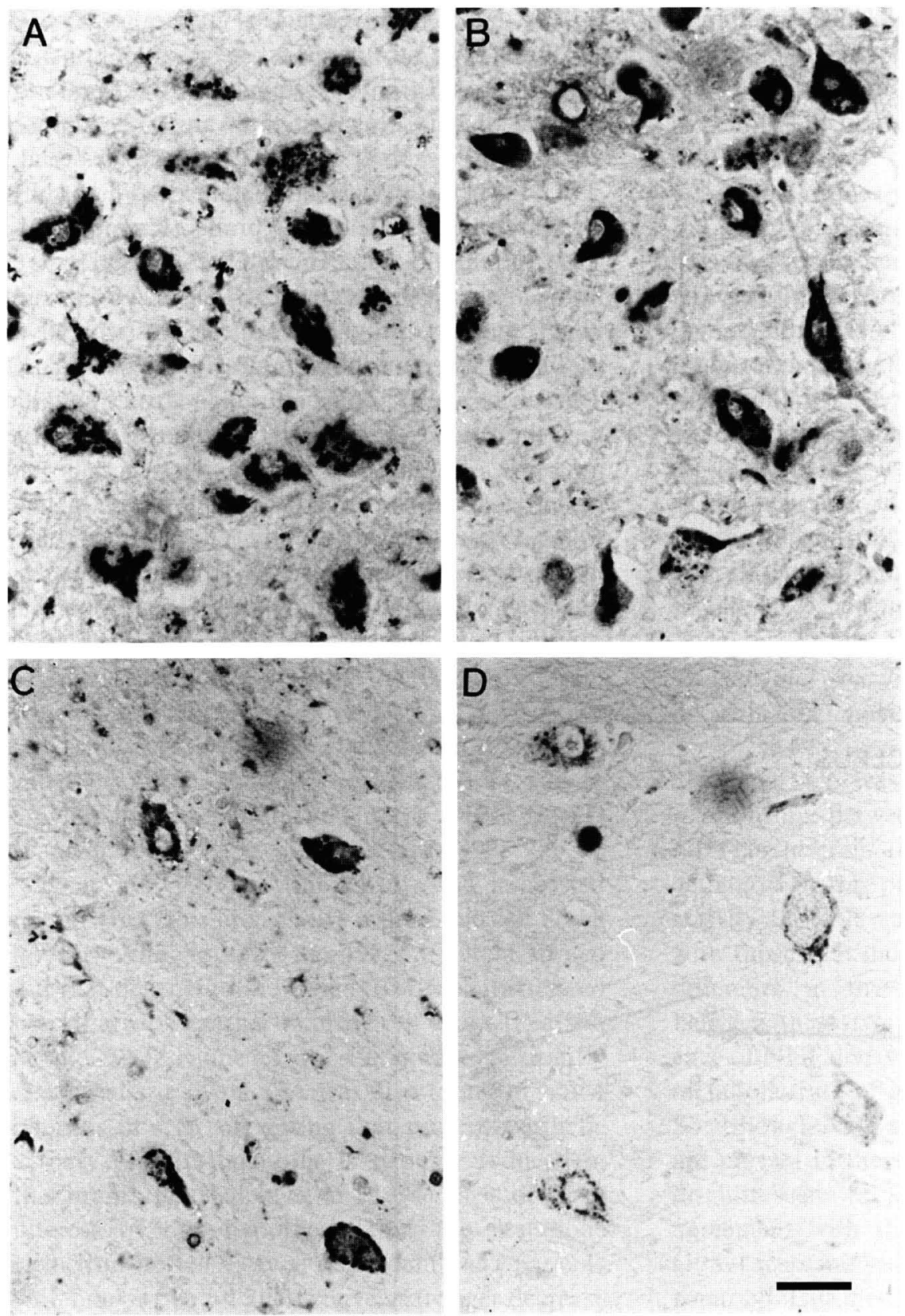

Fig. 6. Immunocytochemical staining of the Golgi apparatus (GA) in the nucleus basalis of Meynert of a (A) young control and (B) old control and (C) young AD patient and (D) old AD patient. Note the similarity between GA of cells of four groups. Scale bar $30 \mu \mathrm{m}$ (from Salehi et al., 1994, with permission). This indicates the reduction in neuronal metabolism in this brain area in AD in the nucleus basalis of Meynert.

1990; Van der Woude et al., 1995). In contrast, even signs of hyperactivation with aging were found in the SON (Hoogendijk et al., 1995; Van der Woude et al., 1995; Fig. 7). As shown by Lucassen et al. (1994) there was indeed a significant increase in activity of vasopressinergic neu- 
rons of the SON during aging, both in controls and $\mathrm{AD}$ patients (Fig. 5), supporting the idea that activation of neurons is accompanied by an absence of AD pathologies (Swaab, 1991).

\section{Pretangle alterations}

Tau proteins belong to the microtubule associate proteins (see chapter by Goedert). Hyperphosphorylated tau as found in $\mathrm{AD}$ patients may prevent tau proteins from binding to microtubules (Lee et al., 1991). This would result in a failure to maintain axonal transport and neuronal shape. Furthermore, it has been suggested that the occurrence of early cytoskeletal changes due to abnormal phosphorylation of tau, would precede the appearance of neurofibrillary degeneration as shown by silver staining (Bancher et al., 1989; Braak et al., 1994).
The hypothalamic nucleus tuberalis lateralis (NTL) shows strong cytoskeletal alterations, as appears from the intense staining with the antibodies Alz-50, tau-1 (against tau), and 3-39 (against ubiquitin) (Swaab et al., 1992; Van de Nes et al., 1993; Fig. 1). However, silver stained NFTs or NPs are rare in the NTL of AD brains (Kremer et al., 1991; Kremer, 1992). The NTL thus represents a brain area that shows an early stage of AD changes that does not progress towards classical silver staining of neuropathological AD hallmarks (Swaab et al., 1992), which made it very suitable for the study of the relationship between the presence of pretangles and changes in neuronal activity. As shown by Salehi et al. (1995a), there was no reduction in the activity of the neurons in this area in AD. Furthermore, comparison of the intensity of Alz-50 staining with Golgi apparatus size did not show any clear relationship, showing

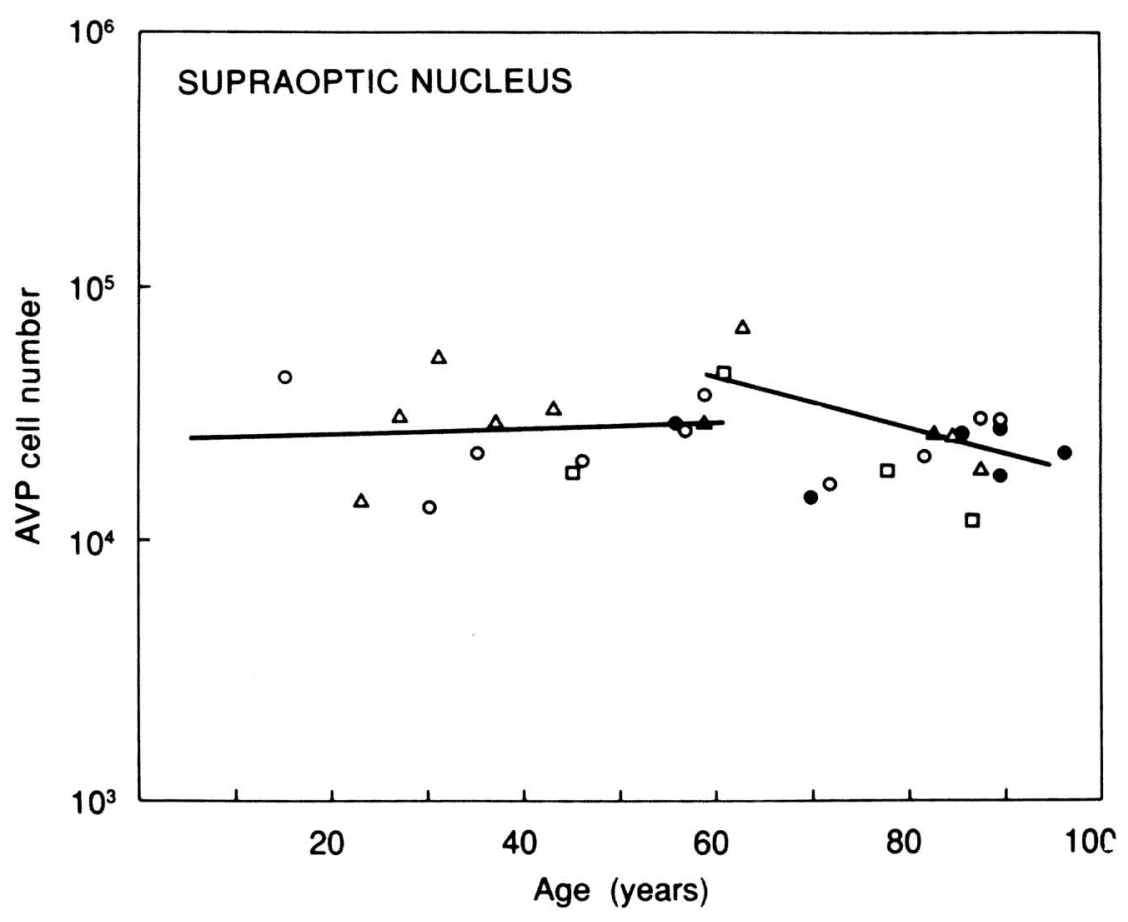

Fig. 7. Linear regression between vasopressin (AVP) cell number in the dorsolateral supraoptic nucleus (SON) and age. Data of male $(\triangle)$ and female $(O)$ control subjects did not differ and were pooled. No statistically significant correlations with age were observed in either young or old subjects. Values of male $(\boldsymbol{\Delta})$ and female $(\bullet)$ AD patients were within the range of the controls (from Van der Woude et al., 1995, with permission). These data show that the SON cells that are activated during the process of aging, both in controls and AD patients (see Fig. 5) and are not lost in AD (Fig. 7). 
that strong cytoskeletal alterations in the NTL are not accompanied by decreased neuronal activity. Pretangle AD changes and reduced metabolic activity are therefore not necessarily related.

\section{Late cytoskeletal alterations (NFTs)}

The occurrence of early cytoskeletal alterations is presumed to be followed by the formation of NFTs that are detectable by silver staining (Bancher et al., 1989). Our finding on the NTL (see above) that there was no relationship between the appearance of early cytoskeletal alterations and protein synthetic ability, raised the question whether AD changes and decreased metabolism are related in other brain areas with late stages of cytoskeletal alterations, i.e. NFTs and NPs, such as the NBM, tuberomamillary nucleus (TM) and CA1 area of the hippocampus.

The NBM is an area of the basal forebrain which is severely affected in AD. This nucleus not only shows early cytoskeletal alterations as indicated by Alz-50 staining, but also NFTs and $\beta$ amyloid accumulation and some NPs in AD (Rudelli et al., 1984; Swaab et al., 1992; Van de Nes et al., 1993). Although it was suggested initially that this area shows a dramatic cell death in AD (Whitehouse et al., 1982; 1983), it turned out that degeneration in the NBM is characterized by cell atrophy rather than by cell death (Pearson et al., 1983; Rinne et al., 1987). A significantly decreased size of the GA was also found in NBM neurons in $\mathrm{AD}$, suggesting that protein synthetic activity of NBM neurons is strongly reduced in this brain area (Salehi et al., 1994). It is of great interest to our hypothesis that the metabolic reduction is APOE type dependent. AD patients with one or two $\varepsilon-4$ alleles have a stronger decrease in neuronal metabolic rate in the NBM (Salehi et al., 1998b in press). As shown by Salehi et al. (1995c), metabolic activity of TM neurons, an area of the hypothalamus which is clearly affected by NFTs (Nakamura et al., 1993), is significantly reduced in $\mathrm{AD}$, which again supports the existence of a relationship between the occurrence of $\mathrm{AD}$ pathology and decreased neuronal activity. The same holds for the CAl area of the hippocampus that is strongly affected by AD changes (West et al., 1994) and where, as shown by Salehi et al. (1995b), neuronal activity was strongly decreased in $\mathrm{AD}$ patients.

In conclusion, the pretangle stage of $\mathrm{AD}$ changes is not necessarily related to changes in metabolic rate, as indicated by our studies on the NTL. However, (i) both the clear reduction in activity in the NBM, TM and CA1 neurons that are affected by later stages of AD, and (ii), on the other hand, the significant increase in activity of the vasopressinergic neurons during aging and AD in the SON, an area where generally no cytoskeletal abnormalities are observed, support the idea that decreased neuronal activity and the occurrence of the classical late stage $\mathrm{AD}$ changes may go together.

Tangles and neuritic plaques (NPs) do not cause decreased metabolic rate

The next step was to study the causality of the relationship between the presence of NPs and NFT in a brain area with decreased metabolic activity. For this purpose we compared metabolic activity of CA1 neurons that did contain NFTs with those that did not. There appeared to be no difference in the size of the Golgi apparatus between these two groups of neurons. The presence of NFT does not seem to decrease the general metabolic rate of a neuron (Salehi et al., 1995b). So although NFT and decreased metabolic activity are present in the same brain area, i.e. CA1, they do not seem to be causally related. This is in agreement with the observation of Gertz et al. (1989) who showed that the presence of intraneuronal NFT in the CA1 area of the hippocampus is not related to another parameter of general metabolic activity, i.e. nucleolar or cell size. This does certainly not exclude the possibility that tangles may decrease the production of certain specific compounds. Indeed, Hatanpää et al. (1996) have shown that cytochrome oxidase subunit III mRNA is decreased in tangle-bearing neurons. 
Neuritic plaques (NPs) are considered by some as later stages of amorphous plaques (Rozemuller et al., 1989, and see before). Because of extensive damage to the neuropil in the vicinity of NPs, they are also called "malignant" plaques (Wisniewski and Wegiel, 1995). Although it is still a matter of controversy, many investigators believe that the $\beta$ amyloid content of the core of the plaques is neurotoxic (see before) and induces neural degeneration. On the other hand, unlike in the case of NFTs, there is no clear relationship between the number of NPs and the severity of dementia (see before) which makes a neurotoxic effect of plaques as a major pathogenetic mechanism in $\mathrm{AD}$ questionable. If a plaque should contain neurotoxic compounds one would expect that the closer a neuron is situated to the plaque, the lower its metabolic rate would be. Our measurements do not support the idea of such a mechanism. There appeared to be no relationship between either the density of NPs or the distance of each NP to the metabolic activity of neighboring neurons (Salehi et al., 1998a). This finding does not support the possibility that neurotoxicity of plaques causes decreased neuronal metabolism in vivo but rather that metabolism and NPs are two basically independent phenomena.

\section{Neuronal activation in older subjects}

Other data in favour of the "use it or lose it" hypothesis are provided by studies on the infundibular nucleus of the hypothalamus of elderly men and post-menopausal women. Strong activational changes were found in neurons expressing estrogen receptor and substance-P mRNA as judged from the pronounced neuronal hypertrophy and the occurrence of larger and double nucleoli. Also marked increases in tachykinin gene expression were found in this nucleus in postmenopausal women (Rance, 1992; Rance and Young 1991; Rance et al., 1990; 1993). These changes are likely to be related to the loss of negative steroid hormone feedback as a result of ovarian failure in women. In men they may be due to testicular failure in combination with reduced circulating testosterone levels (Rance et al., 1993; Ule et al., 1983). Activated neurons have been reported to be still present in this nucleus of women of over 100 years of age (Ule et al., 1983), suggesting that the activated neurons indeed remain intact in old age.

Interestingly, recent information suggests that the postmenopausal activation of the infundibular or arcuate nucleus in women prevents the formation of AD changes in this area (Fig. 8). The sexspecific argyrophilic neurofibrillary changes in the median eminence and infundibular nucleus as observed by Gallyas silver stainings and antibodies to abnormally phosphorylated tau, occur in most men over the age of 60 years but are seldom found in women of the same age (Schultz et al., 1996). The activation of the infundibular nucleus in postmenopausal women is much more pronounced than in men of the same age (Rance, 1992). This observation may, therefore, serve as an extremely good example of the "use it or lose it" concept and illustrates, in addition, that it is quite possible to stimulate successfully a neuronal population in the second half of life.

\section{Brain reserve}

A recently found positive correlation between the age of onset of $\mathrm{AD}$ and premorbid brain size suggests that brain size may be an important determinant for the occurrence of AD symptoms (Schofield et al, 1995; 1997). In addition, the intelligence of Alzheimer's disease patients is positively correlated with premorbid brain volume and negatively with the magnitude of brain atrophy (Mori et al., 1996). A smaller head circumference, an indication for smaller head size, goes together with a longer disease or more rapid progression of Alzheimer's disease (Graves et al., 1996), suggesting that a larger brain may provide protection against Alzheimer's disease or is a determinant of reserves.

Additional relevant observations are the associations reported between low education level and poor performance on mental status examinations that were found in $\mathrm{AD}$ (Mortimer and Graves, 


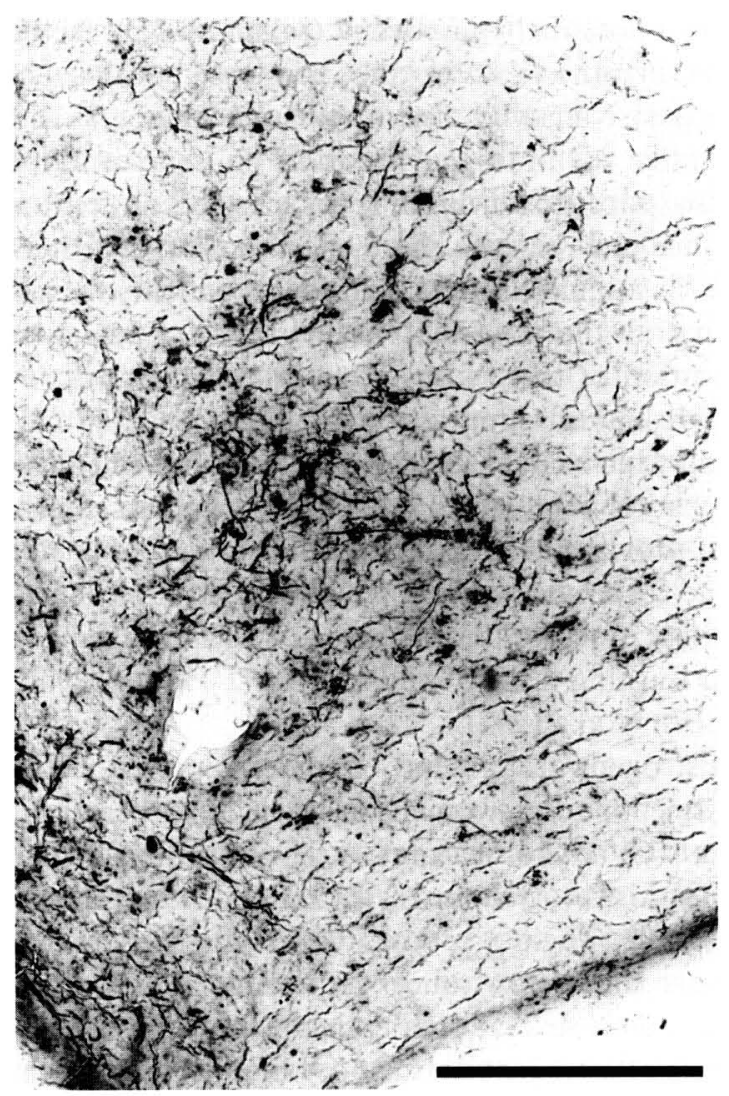

Fig. 8. Mediobasal hypothalamus of a 66-year old male with advanced cytoskeletal pathology stained by Alz-50. Such pathology is rarely present in postmenopausal women, as reported by Schultz et al. (1996). In postmenopausal women this area, that includes the infundibular (or arcuate) nucleus, is strongly activated as a result of ovarian failure (Rance 1992). These observations suggest that the hyperactivity in the mediobasal hypothalamus in postmenopausal women may reduce the risk of developing Alzheimer changes in that area. The bar indicates $0.5 \mathrm{~mm}$.

1993). Several studies have indicated that education may protect against dementia (Boniauto et al., 1995; Fratiglioni et al., 1991; Kondo et al., 1994; Stern et al., 1994; Mortel et al., 1995). However, others could not confirm such an association (Beard et al., 1992) or even seemed to contradict it, because patients with more education were found to have more advanced AD pathology as well as an increased mortality (Stern et al., 1995), yet the authors do not consider this observation as contradictory to the increased reserve hypothesis, since for any level of AD pathology the clinical expression of $\mathrm{AD}$ was less severe in patients with more education. In a recent paper the study of Stern et al. (1995) was not confirmed. On the contrary, relative risk of death decreased as the level of education increased (Geerlings et al., 1997). In addition, occupation was shown to be a stronger indication of risk for dementia than education (Bonaiuto et al., 1995; Mortel et al., 1995). Although it has been suggested that education may increase brain reserve by increasing the density of cortical synapses and thus delaying AD symptoms (Katzman, 1993; Stern et al., 1995), the exact mechanism of the effects of education and occupation on the brain clearly requires further research.

\section{Reactivation as a means of restoring neuronal function in Alzheimer's disease: Clinical studies and therapeutical consequences}

The present review showed that there is a clear reduction in neuronal metabolic activity in various brain areas in $\mathrm{AD}$ patients. Consequently, one may assume that restoration of the activity of neurons, either by pharmacological or nonpharmacological stimuli, would lead to diminishment of cognitive impairment (Swaab, 1991). Although it is not yet clear whether decreased metabolic activity is the primary process in the pathogenesis of $\mathrm{AD}$, recent data show that reactivation of neurons is, in principle, beneficial to $\mathrm{AD}$ patients.

\section{Pharmacological stimuli}

One of the neurotransmitter systems clearly affected in $\mathrm{AD}$ is the cholinergic system. Marked reductions have been reported in cholinergic muscarinic and nicotinic receptor density and also deficits in cortical and hippocampal acetylcholine concentrations and choline acetyltransferase activity have been described. Since the extent of the cholinergic deficit correlates with the degree of cognitive functioning and memory impairment (Lehericy et al., 1993), the cholinergic system has 
been proposed to be a suitable candidate for transmitter replacement therapy. Cholinesterase inhibitors enhance acetylcholine content in the synaptic cleft, which results in restoration of cholinergic nicotinic receptor functioning and glucose metabolism. The application of moderately long-acting cholinesterase inhibitors such as tacrine (tetrahydroaminoacridine, THA), indeed has significant effects on cognitive functioning in AD patients and has even been claimed to slow down the course of the disease (Nordberg, 1992; 1995). Furthermore, the increases in glucose metabolism and nicotinic receptors following tacrine treatment are paralleled by improvements in neuropsychological performance and EEG (Nordberg, 1995). These observations support the concept of $\mathrm{AD}$ as a hypometabolic disorder and indicate that enhanced functional brain activity can be obtained in AD after application of the proper stimulus. However, when effects of tacrine treatment are concerned, it is important to know that positive effects were mainly obtained in mildly to moderately demented patients, suggesting that a too strong hippocampal atrophy or neuronal loss prevents the beneficial effects of such a treatment (Riekkinen et al., 1995). This illustrates that restimulating effects of, e.g., hormone replacement therapy may also hold if only some "functional reserve" in the form of critical amounts of tissue and receptor numbers, is still present. If atrophy has been too strong or hippocampal cell death has already occurred, restimulation, obviously, will not be effective anymore.

A second example of restimulating systems in the aging brain are sex hormones. In aging, declines in AVP fiber density and in AVP-mRNA were observed, particularly in sex steroid-dependent areas (Goudsmit et al., 1988; Dobie et al., 1991; Miller et al., 1989) that coincided with the progressive age-related drop in plasma testosterone levels (Ravid et al., 1987; Goudsmit et al., 1990b). Testosterone supplementation was indeed shown to be able to restore the AVP innervation in old animals (Goudsmit et al., 1988; 1990c, Dobie et al., 1992). Furthermore, since testosterone is aromatized to estrogens in the brain, estrogens form a potentially important (re)stimulating factor as well. In view of the proposed decline in aromatase activity and decreased numbers and affinities of androgen reporters in senescent rat brain, estrogens or brain specific estrogen receptor ligands may be even more effective than testosterone in stimulating sex-steroid dependent mechanisms in the senescent brain. In aged rats, the cessation of the oestrus cycle in circulating estrogen results in suppression of hippocampal function, which could be restored by supplementing oestradiol (Hagino, 1981). Other animal studies also show stimulatory effects of estrogens, but not of testosterone, on e.g. choline acetyltransferase activity in several brain areas as well as on memory and learning tasks (Goudsmit et al., 1990a, 1990d; McBee et al., 1997).

Estrogens are presently frequently prescribed to postmenopausal women, as they have beneficial effects on several features of female aging, such as bone loss (osteoporosis), hot flashes, nightly sweating, vaginal dryness and atrophy, heart disease and colon cancer as well as aging of the skin. Also, several studies have shown beneficial effects of estrogens on memory in postmenopausal women (Fedor-Freybergh et al., 1977; Sherwin, 1988; Philips and Sherwin, 1992; Robinson et al., 1994) and to enhance mental functioning in women with mild to moderate AD (Ohkura et al., 1995; 1994a; 1994b; Honjo et al., 1994). In addition, improvements have been described in attention, memory, calculation, orientation and social interaction following administration of estrogens (Honjo et al., 1989). Postmenopausal estrogen replacement is furthermore considered to protect against Alzheimer's disease (Henderson et al., 1996; Tang et al., 1996; Stephenson et al., 1996). Recent reviews concluded, however, that the evidence of beneficial effects of oestrogens on cognitive function is encouraging but inconclusive, since there is currently inadequate evidence from randomized, controlled trials, to support this conclusion (Haskell et al., 1997; Henderson, 1997). In rat, effects of estrogens have been suggested to be mediated via growth factors such as brain-derived neurotrophic factor (BDNF) and 
NGF. The administration of growth factors may prevent or revert the age-related or experimentally-induced (cholinergic) neuron atrophy. Reduced sensitivity of NBM neurons to NGF may be present in AD. Recent data on the distribution of NGF receptors in the NBM indeed demonstrate that expression of the high affinity receptor trkA is strongly reduced in $\mathrm{AD}$, followed by similar but smaller reductions in trkC and trkB (Salehi et al., 1996). These results indicate that, although NBM neurons of AD patients are not NGF deficient, the degeneration in this area is associated with a decreased expression of NGF receptor subtypes and thus with a reduced responsiveness of NBM neurons to growth factor stimulation in $\mathrm{AD}$ (Salehi et al., 1996).

\section{Non-pharmacological stimuli}

Omental transposition to increase blood vessel development and cerebrovascular perfusion was found to improve the condition of an Alzheimer patient (Goldsmith, 1996), but controlled studies are needed to confirm this effect. Older studies showed that reality orientation - a long-term program of formal didactic group therapy improved cognitive functioning of demented elderly people. This shows that the nature of staff attention is crucial (Woods, 1979; Hanley et al., 1981). A more recent study confirmed the positive effects of reality orientation on Mini Mental States Examination and verbal fluency scores (Zanetti et al., 1995). Also exercise therapy improved cognition in institutionalized geriatric mental patients (Powell et al., 1974). In two studies, elderly demented patients, including AD-patients, received an 'integrity-promoting care' program consisting of increased emotional and intellectual communication and physical activation (Karlsson et al., 1985; Widerlöv et al., 1989). After applying this program for two months, short-term memory and visual perception had improved in the experimental group while they had deteriorated in the control group (Karlsson et al., 1985). Moreover, compared to the experimental group, concentration declined and absent-mindedness increased significantly in the control group. An important additional finding was that the experimental group showed an increase in their mean CSF level of the neuropeptide somatostatin, whereas the control group showed a decrease. In the other study, ADpatients and patients with multi-infarct dementia (MID) received the 'integrity-promoting care' program for 3 months (Widerlöv et al., 1989). Short-term memory, dressing ability and physical activity improved, whereas confusion diminished. Moreover, the reduced CSF level of somatostatin had been elevated in the experimental group, whereas the concentration of vasopressin decreased in both groups, although to a lesser extent in the experimental group.

In a series of experiments, E.J.A. Scherder examined the effects of increased somatosensory input by means of various types of peripheral nerve stimulation (i.e. transcutaneous electrical nerve stimulation (TENS), tactile nerve stimulation, and a combination of both types of stimuli) on memory, and on independent and affective functioning of patients in a relatively early stage of AD (Scherder et al., 1992; 1995a, 1995b, 1995c; 1996; 1998; Table I). In one study, the patients were treated six hours per day, during a six-week period (Scherder et al., 1992), in the other studies a 30-minute-a-day treatment was applied during six weeks. Each treatment period was followed by a treatment-free period of six weeks. The results of these studies show that, compared to controls who received a placebo treatment, various aspects of nonverbal short-term memory, nonverbal and verbal long-term memory, and word fluency of stimulated AD-patients improved. More specifically, these improvements imply that, after treatment, patients were better capable of (1) learning new material, (2) retrieving familiar, categorized information from their memory store, and (3) storing, reversing, and reproducing nonverbal information (Table 1). With respect to independent and affective functioning, patients who were treated participated more independently in daily life, showed a better personal orientation and orientation in place, and enhanced their social interaction with fellow-residents. In addition, 


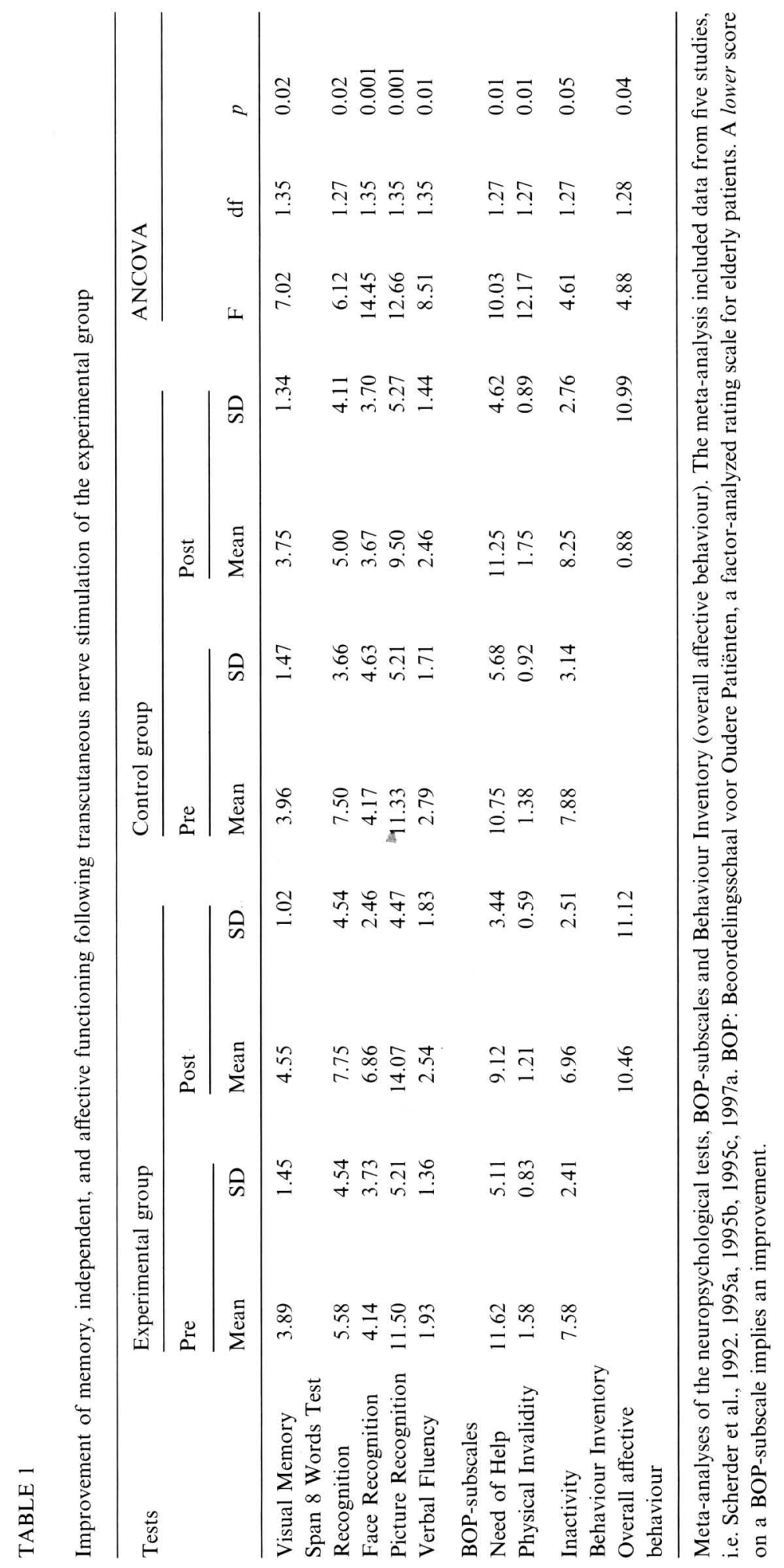


stimulated patients felt less withdrawn, irritable, moody, dejected and gloomy and appeared to be more active and alert, possibly resulting in a decrease in forgetfulness. As in those studies the therapist was present during both the peripheral stimulation of the experimental group and the sham stimulation of the control group, interpersonal communication alone could not explain the treatment effects. However, a positive effect of the combination of peripheral nerve stimulation with interpersonal communication could not be excluded. Consequently, it was examined whether TENS, in the absence of the therapist, could also have a positive influence on the cognitive, and independent and affective functioning of AD-patients (Scherder et al., 1998). Moreover, it was investigated whether TENS had a positive effect on the circadian rest-activity rhythm of AD-patients (Van Someren et al., 1998). The results show that the improvements in nonverbal short- and long-term memory, verbal long-term memory and word fluency are solely due to the electrical stimulus itself. Furthermore, patients who were treated participated more independently in activities of daily life. However, TENS, in the absence of the therapist, appeared to have no beneficial effect on patients' affective functioning. Another finding was that the circadian rest-activity rhythm of stimulated AD-patients improved (see also below), implying an increase in the strength of coupling to Zeitgebers (Van Someren et al., 1998). The results of the clinical studies further revealed that the majority of the effects of peripheral nerve stimulation, both in the presence and absence of the therapist, could not be maintained during the treatment-free period of six weeks. In one study, transcranial electrostimulation in elderly patients with multi-infarct dementia was also found to decrease wandering and nocturnal delirium and to enhance patients' interaction with others (Hozumi et al., 1996). The authors suggest that the transcranial electrical stimulus might partly be mediated through the somato-sensory system.

An age-related decrease in circadian modulation has, among other things, been observed in hormone levels, temperature, electroencephalographic
(EEG) activity, alertness and sleep (Van Someren et al., 1993; Witting et al., 1990). Elderly people start napping during the day and often complain of disturbed sleep during the night. In Alzheimer's disease this fragmentation of the sleep-wake pattern is even more pronounced. The suprachiasmatic nucleus (SCN), which is the biological clock of the brain, is of critical importance in the circadian modulation of behavior and physiology. In aging, and even more so in Alzheimer's disease, a marked reduction in the number of vasopressin-expressing neurons is found (Fig. 9). The combined anatomical, physiological and behavioral findings suggest that a dysfunctional clock may underlie the sleepwake pattern fragmentation (Hofman and Swaab, 1994; Swaab et al., 1985; 1992; 1997), and we therefore tried a number of strategies designed to stimulate the circadian timing system in order to promote preservation of neuronal functioning of the circadian timing system, and thereby to enhance the functionality of the clock. Increased

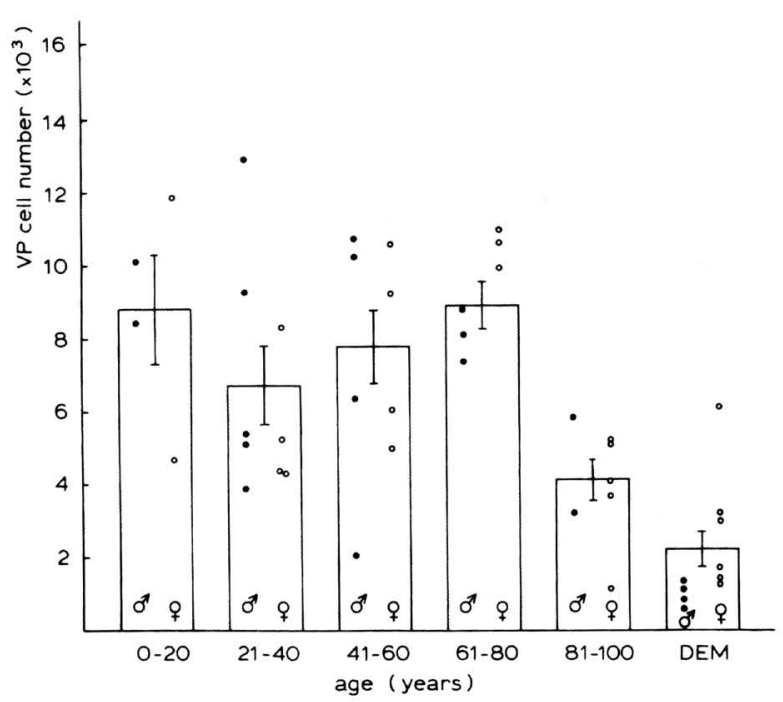

Fig. 9. Number of vasopressin (VP) expressing neurons in the suprachiasmatic nucleus. Note the low values in the 81-100year-old group and the very low numbers in the AD patients (DEM) that were $78 \pm 5$ years of age. The decreased number of cells expressing AVP is considered to be an indication for low metabolic activity of the SCN in old people and $\mathrm{AD}$ patients and the changes in the $\mathrm{SCN}$ in $\mathrm{AD}$ are held responsible for sleep disturbances and nightly restlessness. 
input to the circadian timing system can, among other things, be effectuated by means of bright environmental light, peripheral nerve stimulation and increased levels of physical activity (Fig. 10).

Our studies in aged rats have demonstrated improvement of both functional and anatomical signs of degeneration of the circadian timing system after environmental stimulation. Witting et al. (1993) demonstrated that the decreased amplitude in the circadian distribution of sleep and wakefulness as it is present in old rats, could be restored to the level of young rats by means of increasing the intensity of daytime environmental light. Lucassen et al. (1995) demonstrated that such increased light input counteracted the agerelated decrease in the number of vasopressinexpressing neurons in the rat SCN (Fig. 4).

In human, we have used the rest-activity rhythm as a marker of the functionality of the circadian timing system, because this variable can easily be assessed using actigraphy. An actigraph is a small wrist-worn solid state recorder that continuously assesses the activity level, resulting in a time-series from which the strength of the circadian rhythm can be calculated. In a correlational study, we first investigated which constitutional and environmen-

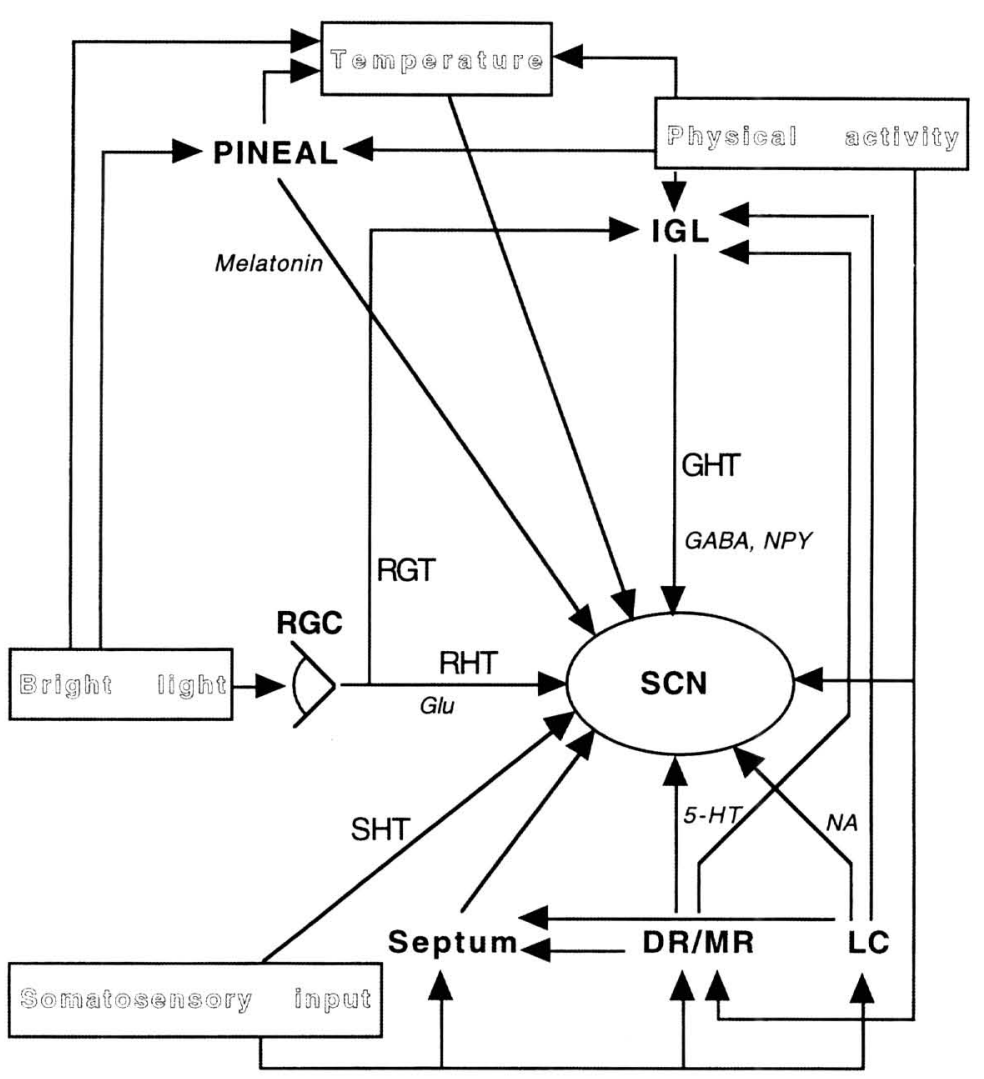

Fig. 10. Schematic overview of the inputs to the suprachiasmatic nucleus and their interactions that may be relevant for the concept of $\mathrm{SCN}$-stimulation. For reasons of clarity, temperature input is only shown for the SCN, whereas thermosensitivity has in fact been demonstrated in the pineal, SCN, septum, raphe nuclei, locus coeruleus and somatosensory afferents. Inputs are in outlined font, structures in bold, tracts in normal font and neurotransmitters and hormones in italics. Abbreviations: 5-HT = 5-hydroxytryptamine (serotonin); DR = dorsal raphe nucleus; GABA = gamma aminobutyric acid; GHT= geniculohypothalamic tract; Glu=glutamate; $\mathrm{IGL}=$ intergeniculate leaflet; $\mathrm{LC}=$ locus coeruleus; $\mathrm{MR}=$ median raphe nucleus; $\mathrm{NA}=$ noradrenalin; $\mathrm{NPY}=$ neuropeptide $\mathrm{Y}$; $\mathrm{RGC}=$ retinal ganglion cells; $\mathrm{RGT}=$ retinogeniculate tract; $\mathrm{RHT}=$ retinohypothalamic tract; $\mathrm{SCN}=$ suprachiasmatic nucleus; SHT $=$ spinohypothalamic tract. (from Van Someren 1997, with permission). 
tal factors were related to the severity of rhythm disturbances in Alzheimer patients. Regression analyses showed the most severe rest-activity rhythm disturbances in patients with a sedentary rather than physically active life style, and in patients exposed to low levels of environmental light (Van Someren et al., 1996). Subsequently, we investigated the effect of additional bright light on rest-activity rhythm disturbances in demented patients. Additional bright light improved the coupling of rest-activity rhythms to stable environmental clues (so called Zeitgebers) in patients with intact vision, but not in patients with severely compromised sight (partial blindness, cataract)
(Van Someren et al., 1997a). An example is given in Figure 11. These results agree with other studies showing improved circadian rhythms and decreased behavioral disorders in Alzheimer patients treated with bright light (Campbell et al., 1988; Hozumi et al., 1990; Okawa et al., 1989; 1991; Satlin et al., 1992).

The effect of additional physical activity was investigated in healthy elderly subjects, since fitness training was not a feasible option for most demented subjects. Fitness training improved the fragmentation of periods of rest and activity that occurs both during normal aging, and very pronounced after SCN-lesions, as known from

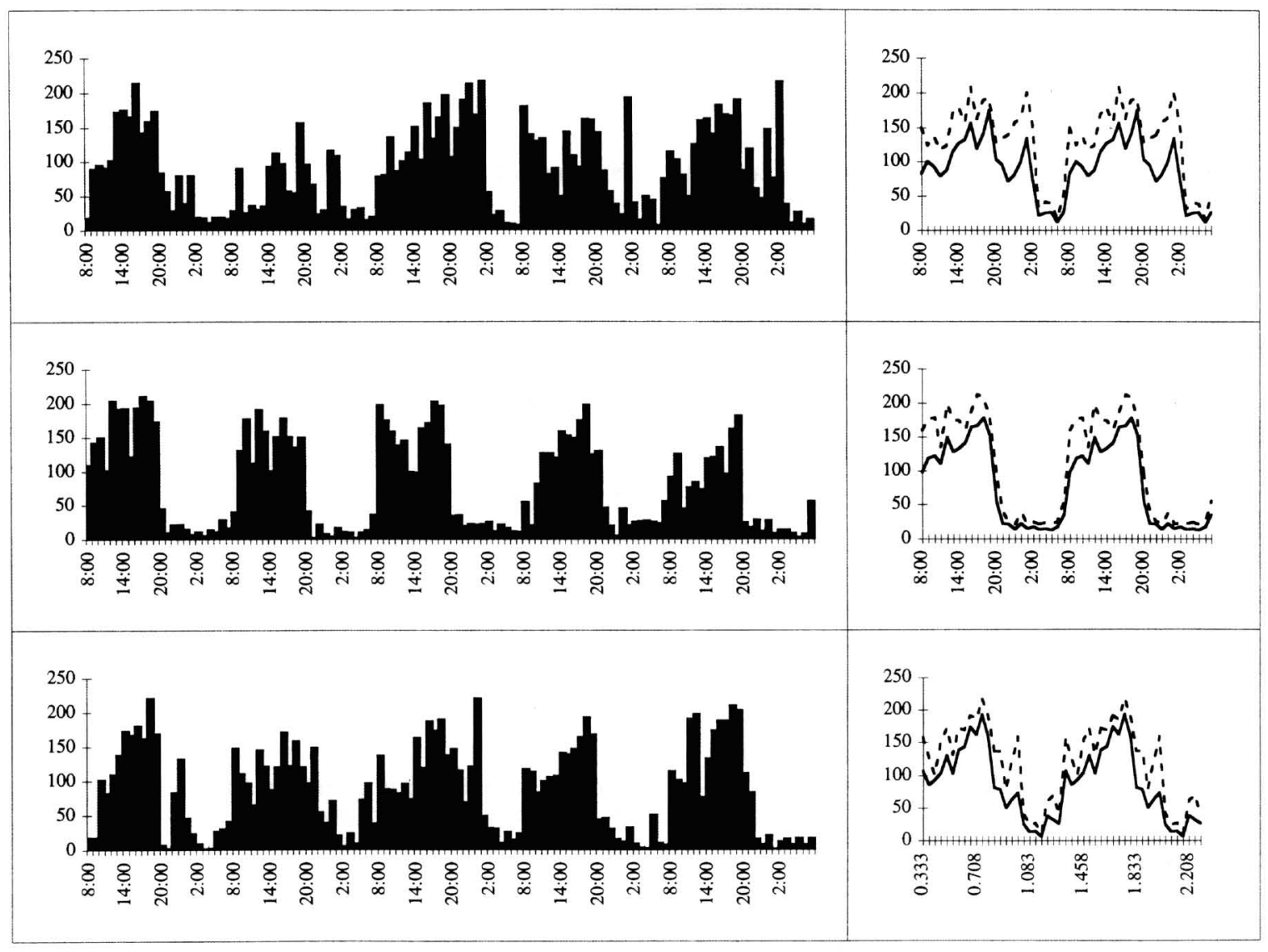

Fig. 11. Raw activity data (left panels) of a patient with Alzheimer's disease assessed three times for five days; before (upper left panel), during (middle left panel) and after (lower left panel) light treatment. The right panels show double plots of the average 2-4 hour activity level (solid line) and one standard deviation above this level (dashed line). Note the decreased variability, the smoother average, and the clearer difference between the day and the night during light treatment (Van Someren et al., 1997a, with permission). 
rat studies (Van Someren et al., 1997b). Whereas the effect of light and activity on the circadian timing system is well documented, the possible effect of somatosensory input to the SCN has only recently been suggested by our group (Van Someren et al., 1998). In rats and squirrel monkeys, it has been demonstrated that the SCN is innervated by direct spinohypothalamic projections conveying somatosensory information (Cliffer et al., 1991; Newman et al., 1996). We have therefore investigated whether additional somatosensory input by means of TENS would provide an alternative means for the activation of SCN neurons. In early-stage demented elderly people, repeated TENS was indeed found to improve the coupling of rest-activity rhythms to Zeitgebers, whereas placebo-treatment was ineffective (Van Someren et al., 1998). Recent studies show that similar effects can also be obtained in advanced stages of AD. The anatomical and functional findings from the reported studies indicate that the SCN retains considerable plasticity in old rats, and, in functional terms, also in healthy and demented elderly subjects. In addition to the clinical relevance of manipulating circadian rhythms, the SCN appears to be a suitable structure for the study of the "use it or lose it" concept (Swaab 1991).

In conclusion, an increasing number of observations indicate that neuronal activation may have positive effects on degenerative changes in aging and AD. An improved balance between DNA damage and repair could be the underlying mechanism, although an alternative mechanism cannot be excluded. The beneficial effects of several types of neuronal activation may differ between different age groups or between different stages of $\mathrm{AD}$. Also, the APOE genotype and presence of functional reserves, whether or not induced by early exposure to a complex environment, profession, education or in relation to genetic history, may interfere with these effects. The effectiveness of neuronal stimulation within the physiological range may strongly depend on the use of the appropriate stimulus and whether the right receptors for certain stimulating factors are still present.
If these requirements are met, neuronal stimulation may indeed be effective in neuronal maintenance during aging and in $\mathrm{AD}$ and can thus be a fruitful basis for the search of a treatment strategy in AD.

The best way to prove that decreased metabolic activity indeed plays a major role in the development of dementia, is of course to show in the future that reversing decreased neuronal metabolism would lead to considerable improvement of cognitive functions. The first series of data support this idea, and the observations that glucose administration or increasing glucose availability by hyperinsulinaemia enhances memory in patients with probable AD (Manning et al., 1993; Craft et al., 1996) not only support the view that $\mathrm{AD}$ is basically a hypometabolic disease, but also indicate that the focus on metabolic stimulation of neurons appears to be a fruitful strategy.

\section{Summary}

1. Alzheimer's disease is a multifactorial disease in which age and APOE- 84 are important risk factors. Various mutations and even viral infections such as herpes simplex (Itzhaki et al., 1997) may play an additional role.

2. The neuropathological hallmarks of Alzheimer's disease (AD), i.e. amorphous plaques, neuritic plaques (NPs), pretangles, neurofibrillary tangles (NFT) and cell death are not part of a single pathogenetic cascade but are basically independent phenomena.

3. Pretangles can occur in neurons from which the metabolic rate is not altered. However, in brain areas where classical AD changes, i.e. NPs and NFTs, are present, such as the CAl area of the hippocampus, the nucleus basalis of Meynert and the tuberomamillary nucleus, a decreased metabolic rate is found. Decreased metabolic rate appears to be an independent phenomenon in Alzheimer's disease. It is not induced by the presence of pretangles, NFT or NPs.

4. Decreased metabolic rate may precede cognitive impairment and is thus an early occurring hallmark of Alzheimer's disease, which, in princi- 
ple, may be reversible. The observation that the administration of glucose or insulin enhances memory in Alzheimer patients also supports the view that Alzheimer's disease is basically a metabolic disease. Moreover, several observations indicate that activated neurons are better able to withstand aging and AD, a phenomenon paraphrased by us as "use it or lose it". It is, therefore, attractive to direct the development of therapeutic strategies towards restimulation of neuronal metabolic rate in order to improve cognition and other symptoms in Alzheimer's disease. A number of pharmacological and non-pharmacological studies support the concept that activation of the brain indeed has beneficial effects on several aspects of cognition and other central functions.

\section{Acknowledgements}

Brain material used was obtained from the Netherlands Brain Bank in the Netherlands Institute for Brain Research, Amsterdam (coordinator: Dr. R. Ravid). We are grateful to Dr. M.A. Hofman for his critical remarks, and to Ms W.T.P. Verweij for her excellent secretarial support. PJL is supported by NWO grant \# 904-34-132. PJL and AS are supported by the Internationale Stichting Alzheimer Onderzoek (ISAO).

\section{References}

Agarwal, S. and Sohal, R.S. (1994) Aging and protein oxidative damage. Mech. Aging Dev., 75: 11-19.

Akiyama, H., Tago, H., Itagaki, S. and McGeer, P.L. (1990) Occurrence of diffuse amyloid deposits in the presubicular parvopyramidal layers in Alzheimer's disease. Acta Neuropath. (Berl.), 79: 537-544.

Allen, S.J., Dawbarn, D. and Wilcock, G.K. (1988) Morphometric immunochemical analysis of neurons in the nucleus basalis of Meynert in Alzheimer's disease. Brain Res., 454: 275-281.

Ames, B.N. (1989) Endogenous oxidative DNA damage, aging, and cancer. Free Radic. Res. Commun., 7: 121-128.

Andrä, K., Abramowski, D., Duke, M., Probst, A., Wiederhold, K-H., Bürki, K., Goedert, M., Sommer, B. and Staufenbiel, M. (1996) Expression of APP in transgenic mice: A comparison of neuron-specific promotors. Neurobiol. Aging, 17: 183-190.
Armanini, M.P., Hutchins, C., Stein, B.A. and Sapolsky, R.M. (1990) Glucocorticoid endangerment of hippocampal neurons is NMDA receptor dependent. Brain Res., 532: 7-12.

Armstrong, R.A., Myers, D. and Smith, C.U.M. (1993) The spatial patterns of plaques and tangles in Alzheimer's disease do not support the 'cascade hypothesis'. Dementia, 4: 16-20.

Armstrong, R.A., Myers, D. and Smith, C.U.M. (1992) Alzheimer's disease: Are cellular neurofibrillary tangles linked to $B / \mathrm{A} 4$ formation at the projection sites? Neurosci. Res. Comm., 11: 171-177.

Arnold, S.E., Hyman, B.T., Flory, J., Damasio, A.R. and Van Hoesen, G.W. (1991) The topographical and neuroanatomical distribution of neurofibrillary tangles and neuritic plaques in the cerebral cortex of patients with Alzheimer's disease. Cerebr. Cortex, 1: 103-116.

Arriagada, P.V., Growdon, J.H., Hedly-Whyte, E.T. and Hyman, B.T. (1992) Neurofibrillary tangles but not senile plaques parallel duration and severity of Alzheimer's disease. Neurology, 42: 631-639.

Bancher, C., Brunner, C., Lassmann, H., Budka, H., Jellinger, K., Wiche, G., Grundke-Iqbal, I., Iqbal, K. and Wisnieswski, H.M. (1989) Accumulation of abnormally phosphorylated tau precedes the formation of neurofibrillary tangles in Alzheimer's disease. Brain Res., 477: 90-99.

Barcikowska, M., Wisniewski, H.M., Bancher, C. and Grundke-Iqbal, I. (1989) About the presence of paired helical filaments in dystrophic neurites participating in the plaque formation. Acta Neuropath. (Berl.), 78: 225-231.

Beal, M.F. (1992a) Does impairment of energy metabolism result in excitotoxic neuronal death in neurodegenerative illnesses? Ann. Neurol., 31: 119-130.

Beal, M.F. (1992b) Mechanisms of excitotoxicity in neurologic diseases. FASEB J., 6: 3338-3344.

Beal, M.F. (1994) Energy, oxidative damage, and Alzheimer's disease: Clues to the underlying puzzle. Neurobiol. Aging, 15: 171-174.

Beal, M.F., Hyman, B.T. and Koroshetz, W. (1993) Do defects in mitochondrial energy metabolism underlie the pathology of neurodegenerative diseases? TINS, 16: 125-131.

Beard, C.M., Kokmen, E., Offord, K.P. and Kurland, L.T. (1992) Lack of association between Alzheimer's disease and education, occupation, marital status, or living arrangement. Neurology, 42: 2063-2068.

Benzi, G. and Moretti, A. (1995) Are reactive oxygen species involved in Alzheimer's disease? Neurobiol. Aging, 16: 661674.

Bird, T.D., Sumi, S.M., Nemens, E.J., Nochlin, D., Schellenberg, G., Lampe, T.H., Sadovnick, A., Chui, H., Miner, G.W. and Tinklenberg, J. (1989) Phenotypic heterogeneity in familial Alzheimer's disease: A study of 24 kindreds. Ann. Neurol., 25: 12-25.

Black, J.E., Zelazny, A.M. and Greenough, W.T. (1991) Cappillary and mitochondrial support of neural plasticity in adult rat visual cortex. Exp. Neurol., 111: 204-209. 
Blacker, D., Wilcox, M.A., Laird, N.M., Rodes, L., Horvath, S.M., Go, R.C.P., Perry, R., Watson, Jr., B., Bassett, S.S., McInnis, M.G., Albert, M.S., Hyman, B.T. and Tanzi, R.E. (1998) Alpha-2 macroglobulin is genetically associated with Alzheimer disease. Nature Genetics, 19: 357-360.

Bondareff, W., Mountjoy, C.Q. and Roth, M. (1982) Loss of neurons of origin of the adrenergic projection to cerebral cortex (nucleus locus ceruleus) in senile dementia. Neurology, 32: $164-168$.

Bonaiuto, S., Rocca, W.A., Lippi, A., Giannandrea, E., Mele, M., Cavarzeran, F. and Amaducci, L. (1995) Education and occupation as risk factors for dementia: A population-based case-control study. Neuroepidemiology, 14: 101-109.

Bouras, C., Hof, P.R., Giannakopoulos, P., Michel, J-P. and Morrison, J.H. (1994) Regional distribution of neurofibrillary tangles and senile plaques in the cerebral cortex of elderly patients: A quantitative evaluation of a one-year autopsy population from a geriatric hospital. Cereb. Cort., 4: 138-150.

Bowen, D.M., Smith, C.B., White, P., Flack, R.H.A., Carrasco, L.H., Gedye, J.L. and Davidson, A.N. (1977) Chemical pathology of the organic dementias. II. Quantitative estimation of cellular changes in post-mortem brains. Brain, 100: 427-453.

Braak, H. and Braak, E. (1995) Staging of Alzheimer's diseaserelated neurofibrillary changes. Neurobiol. Aging, 16: 271-284.

Braak, H. and Braak, E. (1991) Neuropathological staging of Alzheimer-related changes. Acta Neuropath. (Berl.), 82: 239 259.

Braak, H., Braak, E. and Grundke-Iqbal, I. (1986) Occurrence of neuropil threads in the senile human brain and in Alzheimer's disease: A third location of paired helical filaments outside of neurofibrillary tangles and neuritic plaques. Neurosci. Lett., 65: 351-355.

Braak, H. and Braak, E. (1990) Alzheimer's disease: Striatal amyloid deposits and neurofibrillary changes. J. Neuropath. Exp. Neurol., 49: 215-224.

Braak, H., Braak, E., Bohl, J. and Lang, W. (1989a) Alzheimer's disease: Amyloid plaques in the cerebellum. J. Neurol. Sci., 93: 277-287.

Braak, H., Braak, E., Ohm, T. and Bohl, J. (1989b) Alzheimer's disease: Mismatch between amyloid plaques and neuritic plaques. Neurosci. Lett., 103: 24-28.

Braak, E., Braak, H. and Mandelkow, E-M. (1994) A sequence of cytoskeletal changes related to the formation of neurofibrillary tangles and neuropil threads. Acta Neuropathol. (Berl.), 8733: 554-567.

Campbell, S.S., Kripke, D.F., Gillin, J.C. and Hrubovcak, J.C. (1988) Exposure to light in healthy elderly subjects and Alzheimer's patients. Physiol. Behav., 42: 141-144.

Campbell, S.S. and Dawson, D. (1991) Bright light treatment of sleep disturbance in older subjects. Sleep Res., 20: 448.

Chagnon, P., Betard. C., Robataille, Y., Cholette, A. and Gauvreau, D. (1995) Distribution of cytochrome oxidase activity in various neurodegenerative diseases. Neuroreport, 6: 711-715.

Chan-Palay, V. and Asan, E. (1989) Alterations in catecholamine neurons of the locus coeruleus in senile dementia of the Alzheimer type and in Parkinson's disease with and without dementia and depression. J. Comp. Neurol., 287: 373-392.

Chandrasekaran, K., Giordano, T., Brady, D.R., Stoll, J., Martin, L.J. and Rapoport, S.I. (1994) Impairment in mitochondrial cytochrome oxidase gene expression in $\mathrm{Al}$ zheimer's disease. Mol. Brain Res., 24: 336-340.

Cliffer, K.D., Burstein, R. and Giesler, G.J. (1991) Distributions of spinothalamic, spinohypothalamic, and spinotelencephalic fibers revealed by anterograde transport of PHA-L in rats. J. Neurosci., 11: 852-868.

Cordts, R. and Partridge, L. (1996) Courtship reduces longevity of male Drosophila melanogaster. Anim. Behav., 52: 269-278.

Craft, S., Newcomer, J., Kanne, S., Dagogo-Jack, S., Cryer, P., Sheline, Y., Luby, J., Dagogo-Jack, A. and Alderson, A. (1996) Memory improvement following induced hyperinsulinemia in Alzheimer's disease. Neurobiol. Aging., 17: $123-130$.

Crystal, H., Dickson, D., Fuld, P., Masur, D., Scott, R., Mehler, M., Masdeu, J., Kawas, C., Aronson, M. and Wolfson, L. (1988) Clinico-pathologic studies in dementia: Nondemented subjects with pathologically confirmed Alzheimer's disease. Neurology, 38: 1682-1687.

Davies, L., Wolska, B., Hilbich, C., Multhaup, G., Martins, R., Simms, G., Beyreuther, K. and Masters, C.L. (1988) A4 amyloid protein deposition and the diagnosis of Alzheimer's disease: Prevalence in aged brains determined by immunocytochemistry compared with conventional neuropathologic techniques. Neurology, 38: 1688-1693.

Davis, R.E., Miller, S., Herrnstadt, C., Ghosh, S.S., Fahy, E., Shinobu, L.A., Galaskos, D., Thal, L.J., Flint Beal, M. and Howell, N. (1997) Mutations in mitochondrial cytochrome c oxidase genes segregate with late-onset Alzheimer disease. Proc. Natl. Acad. Sci. USA, 94: 4526-4531.

De Lacalle, S., Iraizoz, I. and Ma Conzalo, L. (1991) Differential changes in cell size and number in topographic subdivisions of human basal nucleus in normal aging. Neuroscience, 43: 445-456.

DeLaere, P., Duyckaerts, C., Masters, C.L. and Beyreuther, K. (1990) Large amounts of neocortical $\beta$ A4 deposits without neuritic plaques nor tangles in psychometrically assessed, non-demented person. Neurosci. Lett., 116: 87-93.

DeLaere, P., Yi, H.E., Fayet, G., Duyckaerts, C. and Hauw, JJ. (1993) BA4 deposits are constant in the brain of the oldest old: an immunohistochemical study of 20 French centenarians. Neurobiol. Aging, 14: 191-194.

Dickson, D.W., Farlo, J., Davies, P., Crystal, H., Fuld, P. and Yen, S-HC. (1988) Alzheimer's disease: A double-labelling immunohistochemical study of senile plaques. Am. J. Path., 132: 86-101. 
Dobie, D.J., Miller, M.A., Raskind, M.A. and Dorsa, D.M. (1992) Testosterone reverses a senescent decline in extrahypothalamic vasopressin MRNA. Brain Res., 583: 247252.

Dobie, D.J., Miller, M.A., Urban, J.H., Raskind. M.A. and Dorsa, D.M. (1991) Age-related decline of vasopressin mRNA in the bed nucleus of the stria terminalis. Neurobiol. Aging, 12: 419-423.

Doebler, J.A., Markesbery, W.R., Anthony, A., Davies, P., Scheff, S.W. and Rhoads, R.E. (1988) Neuronal RNA in relation to Alz-50 immunoreactivity in Alzheimer's disease. Ann. Neurol., 23: 20-24.

Duyckaerts, C., Delaere, P., Poulain, V., Brion, J-P. and Hauw, J-J. (1988) Does amyloid precede paired helical filaments in the senile plaque? A study of 15 cases with graded intellectual status in aging and Alzheimer disease. Neurosci. Lett., 91: $354-359$.

Duyckaerts, C., Hauw, J-J., Bastenaire, F., Piette, F., Poulain, C., Rainsard, V., Javoy-Agid, F. and Berthaux, P. (1986) Laminar distribution of neocortical senile plaques in senile dementia of the Alzheimer type. Acta Neuropathol. (Berl), 70: 249-256.

Elsworth, J.D., Deutsch, A.Y., Redmond, D.E. Jr., Taylor, J.R., Sladek, J.R. Jr. and Roth, R.H. (1989) Symptomatic and asymptomatic 1-methyl4-phenyi- 1,2,3,6-tetrahydropyridine treated primates: Biochemical changes in striatal regions. Neuroscience, 33: 323-331.

Emre, M., Geula, C., Ransil, B.J. and Mesulam, M-M. (1992) The acute neurotoxicity and effects on cholinergic axons of interacerebrally injected $\beta$ amyloid in the rat brain. Neurobiol. Aging, 13: 553-560.

Falkenberg, T., Mohammed, K.A., Henriksson, B., Peisson, H., Winblad, B. and Lindefors, N. (1992) Increased expression of brain-derived neurotrophic factor mRNA is associated with improved spatial memory and enriched environment Neurosci. Lett., 138: 153-156.

Fedor-Freybergh, P. (1977) The influence of oestrogen on the well-being and mental performance in climacteric and postmenopausal women. Acta Obstet. Gynaecol Scand., 64: 65-69.

Foster, N.L., Chase, T.N., Mansi, L., Brooks, R., Fedio, P., Patronas, N.J. and Di Chiro, G. (1984) Cortical abnormalities in Alzheimer's disease. Ann. Neurol., 16: 649-654.

Fratiglioni, L., Grut, M., Forsell, Y., Viitanen, M., Grafstrom, M., Holmen, K., Ericsson, K., Backman, L., Ahlbom, A. and Winblad, B. (1991) Prevalence of Alzheimer's disease and other dementias in an elderly urban population: Relation with age, sex, and education. Neurology, 41: 1886-1892.

Games, D., Adams, D., Alessandrini, R., Barbour, R., Berthelette, P., Blackwell, C., Carr, T., Clemens, J., Donaldson, T., Gillespie, F., Guido, T., Hagopian, S., Johnson-Wood, K., Khan, K., Lee, M., Liebowitz, P., Lieberburg, I., Little, S., Masliah, E., McConlogue, L., Montoya-Zavala, M., Mucke, L., Paganini, L., Penniman, E., Powe, M., Schenk, D.,
Seubert, P., Snyder, B., Soriano, F., Tan, H., Vital, J., Wadsworth, S., Wolozin, B. and Zhao, J. (1995) Alzheimer type neuropathology in transgenic mice overexpressing V717F $\beta$-amyloid precursor protein. Nature, 373: 523-527.

Geerlings, M.I., Deeg, D.J.H., Schmand, B., Lindeboom, J. and Jonker, C. (1997) Increased risk of mortality in Alzheimer's disease patients with higher education? A replication study. Neurology, 49: 798-802.

Gensler, H.L. and Bernstein, H. (1981) DNA damage as the primary cause of aging. Quart. Rev. Biol., 56: 279-303.

German, D.C., Manaye, K.F., White III, C.L., Woodward, D.J., McIntire, D.D., Smith, W.K., Kalaria, R.N. and Mann, D.M.A. (1992) Disease-specific patterns of locus coeruleus cell loss. Ann. Neurol., 32: 667-676.

Gertz, H.J., Schoknecht, G., Krüger, H. and Cervos-Navarro, J. (1989) Stability of cell size and nucleolar size in tanglebearing neurons of hippocampus in Alzheimer's disease. Brain Res., 487: 373-375.

Goldsmith, H.S. (1996) Omental transposition for Alzheimer's disease. Neurological Res., 18: 103-108.

Gómez-Isla, T., Hollister, R., West, H., Mui, S., Growdon, J.H., Petersen, R.C., Parisi, J.E. and Hyman, B.T. (1997) Neuronal loss correlates with but exceeds neurofibrillary tangles in Alzheimer's disease. Ann. Neurol., 41: 17-24.

Goudsmit, E., Van de Poll, N.E. and Swaab, D.F. (1990d) Testosterone fails to reverse spatial memory decline in aged rats and impairs retention in young and middle-aged animals. Behav. Neural Biol., 53: 6-20.

Goudsmit, E., Fliers, E. and Swaab, D.F. (1988) Testosterone supplementation restores vasopressin innervation in the senescent rat brain. Brain Res., 473: 306-313.

Goudsmit, E., Feenstra, M.G. and Swaab, D.F. (1990a) Central monoamine metabolism in the male Brown-Norway rat in relation to aging and testosterone. Brain Res. Bull., 25: 755 763.

Goudsmit, E., Hofman, M.A., Fliers, E. and Swaab, D.F. (1990b) The supraoptic and paraventricular nuclei of the human hypothalamus in relation to sex, age and Alzheimer's disease. Neurobiol. Aging, 11: 529-536.

Goudsmit, E., Luine, V.N. and Swaab, D.F. (1990c) Testosterone locally increases vasopressin content but fails to restore choline acetyltransferase activity in other regions in the senescent male rat brain. Neurosci. Lett., 112: 290296.

Graves, A.B., Mortimer, J.A., Larson, E.B., Wenzlow, A., Bowen, J.D. and McCormick, W.C. (1996) Head circumference as a measure of cognitive reserve association with severity of impairment in Alzheimer's disease. Br. J. Psychiatry, 169: 86-92.

Greenberg, B.D., Savage, M.J., Howland, D.S., Ali, S.M., Siedlak, S.L., Perry, G., Siman, R. and Scott, R.W. (1996) APP transgenesis: Approaches toward the development of animal models for Alzheimer disease neuropathology. Neurobiol. Aging, 17: 153-171. 
Guillemette, J.G., Wong, L., Crapper McLachlan, D.R. and Lewis, P.N. (1986) Characterization of messenger RNA from the cerebral cortex of control and Alzheimer-afflicted brain. J. Neurochem., 47: 987-997.

Hagino, N. (1981) Aged limbic system interations of estrogen with catecholaminergic and peptidergic synaptic transmissions. Biomed. Res., 2: 85-108.

Hanley, I.G., McGuire, R.J. and Boyd, W.D. (1981) Reality orientation and dementia: A controlled trial of two approaches. Brit. J. Psychiatr., 138: 10-14.

Hardy, J. (1997) The Alzheimer family of diseases: Many etiologies, one pathogenesis. Proc. Natl. Acad. Sci. USA, 94: 2095-2097.

Harman, D. (1994) Free-radical theory of aging. Increasing the functional lifespan. In: I.Z.-Nagy, D. Harman. K. Kitani (Eds.) Pharmacology of aging processes. Ann. N.Y. Acad. Sci., vol. 717, The New York Academy of Sciences, New York, pp. 1-15.

Haskell, S.G., Richardson, E.D. and Horwitz, R.I. (1997) The effect of estrogen replacement therapy on cognitive function in women: A critical review of the literature. J. Clin. Epidemiol., 50: 1249-1264.

Hatanpää, K., Brady, D.R., Stoll, J., Rapoport, S.I. and Chandrasekaran, K. (1996) Neuronal activity and early neurofibrillary tangles in Alzheimer's disease. Ann. Neurol., 40: $411-420$.

Haxby, J.V., Grady, C.L., Koss, E., Horwitz, B., Schapiro, M., Friedland, R.P. and Rapoport, S.I. (1988) Heterogenous anterior-posterior metabolic patterns in dementia of the Alzheimer type. Neurology, 38: 1853-1863.

Henderson, V.W., Watt, L. and Buckwalter, J.G. (1996) Cognitive skills associated with estrogen replacement in women with Alzheimer's disease. Psychoneuroendocrinology, 21: $421-430$.

Henderson, V.W. (1997) Estrogen replacement therapy for the prevention and treatment of Alzheimer's disease. CNS Drugs, 8: 343-351

Higuchi, M., Arai, H., Nakagawa, T., Higuchi, S., Muramatsu, T., Matsushita, S., Kosaka, Y-i, Itoh, M. and Sasaki, H. (1997) Regional cerebral glucose utilization is modulated by the dosage of apoliprotein E type 4 allele and $\alpha 1$-antichymotrypsin type A allele in Alzheimer's disease. NeuroReport, 8: 2639-2643.

Hock, C., Villringer, K., Müller-Spahn, F., Wenzel, R., Heekeren, H., Schuh-Hofer, S., Hofmann, M., Minoshima, S., Schwaiger, M., Dirnagl, U. and Villringer, A. (1997) Decrease in parietal cerebral hemoglobin oxygenation during performance of a verbal fluency task in patients with Alzheimer's disease monitored by means of near-infrared spectroscopy (NIRS) - Correlation with simultaneous rCBFPET measurements. Brain Res., 755: 293-303.

Hofman, M.A. and Swaab, D.F. (1994) Alterations in circadian rhythmicity of the vasopressin-producing neurons of the human suprachiasmatic nucleus (SCN) with aging. Brain Res., 651: 134-142.
Holcomb, L., Gordon, M.N., McGowan, E., Yu, X., Benkovic, S., Jantzen, P., Wright, K., Saad, I., Mueller, R., Morgan, D., Sanders, S., Zehr, C., O'Campo, K., Hardy, J., Prada, CM., Eckman, C., Younkin, S., Hsiao, K. and Duff, K. (1998) Accelerated Alzheimer-type phenotype in transgenic mice carrying both mutant amyloid precursor protein and presenillin 1 transgenes. Nature Med., 4: 97-100.

Honjo, H., Ogino, Y. and Naitoh, K. (1989) In vivo effects by estrone sulfate on the central nervous system-senile dementia (Alzheimer's type). J. Steroid Biochem. Mol. Biol., 34: 511515.

Honjo, H., Tanaka, K., Kashiwagi, T., Urabe, M., Okada, H., Hayashi, M. and Hayashi, K. (1994) Senile dementiaAlzheimer's type and estrogen. Horm. Metab. Res., 27: 204-207.

Hoogendijk, W.J.G., Pool, C.W., Troost, D., Van Zwieten, E.J. and Swaab, D.F. (1995) Image-analyzer-assisted morphometry of the locus coeruleus in Alzheimer's disease, Parkinson's disease and amyotrophic lateral sclerosis. Brain, 118: 131-143.

Hoyer, S. (1992) Oxidative energy metabolism in Alzheimer brain. Studies in early-onset and late-onset cases. Molec. Chem. Neuropathol., 16: 207-224.

Hoyer, S. (1995b) Age-related changes in cerebral oxidative metabolism. Drugs and Aging, 6: 210-218.

Hoyer, S., Oesterreich, K. and Wagner, O. (1988) Glucose metabolism as the site of the primary abnormality in earlyonset dementia of Alzheimer type? J. Neurol., 235: 143148.

Hoyer, S., Nitsch, R. and Oesterreich, K. (1991) Predominant abnormality in cerebral glucose utilization in late-onset dementia of the Alzheimer type: A cross-sectional comparison against advanced late-onset and incipient early-onset cases. J. Neural Transm., 3: 1-14.

Hoyer, S. (1995) Brain metabolism during aging, In: A. Macieira-Coelho (Ed.), Molecular basis of aging, CRC Press, Boca Raton, USA, pp. 493-510.

Hozumi, S., Okawa, M., Mishima, K., Hishikawa, Y., Hori, H. and Takahashi, K. (1990) Phototherapy for elderly patients with dementia and sleep-wake rhythm disorders - A comparison between morning and evening light exposure. Jpn.J. Psychiatry Neurol., 44: 813-814.

Hozumi, S., Hori, H., Okawa, M., Hishikawa, Y. and Sato, K. (1996) Favorable effect of transcranial electrostimulation on behavior disorders in elderly patients with dementia: A double-blind study. Intern. J. Neurosc., 88: 1-10.

Hsiao, K., Chapman, P., Nilsen, S., Eckman, C., Harigaya, Y., Younkin, S., Yang, F. and Cole, C. (1996) Correlative memory deficits, $\mathrm{A} \beta$ elevation, and amyloid plaques in transgenic mice. Science, 274: 99-102.

Hutchin, T.P., Heath, P.R., Pearson, R.C.A. and Sinclair, A.J. (1997) Mitochondrial DNA mutations in Alzheimer's disease. Biochem. Biophys. Res. Comm., 241: 221-225.

Hyman, B.T., Van Hoesen, G.W., Kromer, L.J. and Damasio, A.R. (1986) Perforant pathway changes and the memory 
impairment of Alzheimer's disease. Ann. Neurol., 20: 472481 .

Irizarry, M.C., McNamara, M., Fedorchak, K., Hsiao, K. and

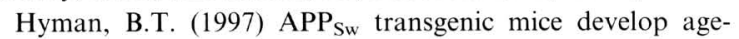
related $\mathrm{A} \beta$ deposits and neuropil abnormalities, but no neuronal loss in CA1. J. Neuropathol. Exp. Neurol., 56: 965973.

Itzhaki, R.F., Lin, W.R., Shang, D., Wilcock, G.K., Faragher, B. and Jamieson, G.A. (1997) Herpes simplex virus type 1 in brain and risk of Alzheimer's disease. Lancet, 349: 241-244.

Joachim, C.L., Morris, J.H. and Selkoe, D.J. (1989) Diffuse senile plaques occur commonly in the cerebellum in $\mathrm{Al}-$ zheimer's disease. Am. J. Pathol., 135: 309-319.

Joynt, R.J. and McNeill, T.H. (1984) Neuropeptides in aging and dementia. Peptides, 5: 269-274.

Jucker, M., Walker, L.C., Martin, L.J., Kitt, C.A., Kleinman, H.K., Ingram, D.K. and Price, D.L. (1992) Age-associated inclusions in normal and transgenic mouse brain. Science, 255: 1443-1445.

Kalaria, R.N. and Harik, S.I. (1989) Reduced glucose transporter at the blood-brain barrier and in cerebral cortex in Alzheimer disease. J. Neurochem., 53: 1083-1088.

Kalus, P., Braak, H., Braak, E. and Bohl, J. (1989) The presubicular region in Alzheimer's disease: Topography of amyloid deposits and neurofibrillary changes. Brain Res., 494: 198-203.

Kammesheidt, A., Boyce, F.M., Spanoyannis, A.F., Cummings, B.J., Ortegon, M., Cotman, C., Vaught, J.L. and Neve, R.L. (1992) Deposition of $\beta / A 4$ immunoreactivity and neuronal pathology in transgenic mice expressing the carboxy terminal fragment of the Alzheimer amyloid precursor in the brain. Proc. Natl. Acad. Sci. USA, 89: 1085710861.

Kang, J., Lemaire, H-G., Unterbeck, A., Salbaum, J.M., Masters, C.L., Grzeschik, K-H., Multhaup, G., Beyreuther, K. and Muller-Hill, B. (1987) The precursor of Alzheimer's disease amyloid A4 protein resembles a cell-surface receptor. Nature, 325: 733-736.

Karlsson, I., Widerlöv, E., Melin, E.V., Nyth, A., Brane, G.A.M., Rybo, E., Rehfeld, J.F., Bissette, G. and Nemeroff, C.B. (1985) Changes of CSF neuropeptides after environmental stimulation in dementia. Nordisk Psykiatrisk Tidsskrift, 39: 75-81.

Katzman, R., Terry, R.D., DeTeresa, R., Brown, T., Davies, P., Fuld, P., Renbing, X. and Peck, A. (1987) Clinical, pathological and neurochemical changes in dementia, a subgroup with preserved mental status and numerous neocortical plaques. Ann. Neurol., 23: 138-144.

Katzman, R. (1993) Education and the prevalence of dementia and Alzheimer's disease. Neurology, 43: 13-20.

Kawabata, S., Higgins, G.A. and Gordon, J.W. (1991) Amyloid plaques, neurofibrillary tangles and neuronal loss in brains of transgenic mice overexpressing a C-terminal fragment of human amyloid precursor protein. Nature, 354: 476-478.
Kish, S.J., Shannak, K., Rajput, A., Deck, J.H.N. and Homykiewicz, O. (1992b) Aging produces a specific pattern of striatal dopamine loss: Implications for the etiology of idiopathic Parkinson's disease. J. Neurochem., 58: 642-648.

Kish, S.J., Bergeron, C., Rajput, A., Dozic, S., Mastrogiacomo, F., Chang, L.-J., Wilson, J.M., DiStefano, L.M. and Nobrega, J.N. (1992a) Brain cytochrome oxidase in Alzheimer's disease. J. Neurochem., 59: 776-779.

Kondo, K., Niino, M. and Shido, K. (1994) A case-control study of Alzheimer's disease in Japan - significance of lifestyles. Dementia, 5: 314-326.

Kowall, N.W. and Kosik, K.S. (1987) Axonal disruption and aberrant localization of tau protein characterize the neuropil pathology of Alzheimer's disease. Ann. Neurol., 22: 639-643.

Kowall, N., McKee, A.C., Yankner, B.A. and Beal, M.F. (1992) In vivo neurotoxicity of beta-amyloid $[\beta(1-40)]$ and $\beta(25-35)$ fragment. Neurobiol. Aging, 13: 537-542.

Kremer, H.P.H., Swaab, D.F., Bots, G.Th.A.M., Fisser, B., Ravid, R. and Roos, R.A.C. (1991) The hypothalamic lateral tuberal nucleus in Alzheimer's disease. Ann. Neurol., 29: 279 284.

Kremer, H.P.H. (1992) The hypothalamic lateral tuberal nucleus: normal anatomy and changes in neurological diseases. In: DF Swaab, MA Hofman, M Mirmiran, R Ravid and FW van Leeuwen (Eds), The Human Hypothalamus in Health and Disease, Progress in Brain Research, Vol 93, Elsevier, Amsterdam, pp. 249-263.

Kumar, A., Newberg, A., Alavi, A., Berlin, J., Smith, R. and Reivich, M. (1993) Regional cerebral glucose metabolism in late-life Alzheimer disease: A preliminary positron emission. Proc. Natl. Acad. Sci. USA, 90: 7019-7023.

Landfield, P.W. and Eldridge, J.C. (1991) The glucocorticoid hypothesis of brain aging and neurodegeneration: Recent modifications. Acta Endocrinol., 125: 5464.

Lee, V.M., Balin, B.J., Otvos, L. Jr. and Trojanowski, J.Q. (1991) A68: A major subunit of paired helical filaments and forms of normal Tau. Science, 251: 675-678.

Lehericy, S., Hirsch, E.C., Cervera-Pierot, P., Hersh, L.B., Bakchine, S., Piette, F., Duyckaerts, C., Hauw, J.J., JavoyAuid, F. and Agid, Y. (1993) Heterogeneity and selectivity of the degeneration of cholinergic neurons in the basal forebrain of patients with Alzheimer's disease. J. Comp. Neurol., 330: 15-31.

Levy-Lahad, E., Wijsman, E.M., Nemens, E., Anderson, L., Goddard, K.A.B., Weber, E., Bird, T.D. and Schellenberg, G.D. (1995) A familial Alzheimer's disease locus on chromosome 1. Science, 269: 970-973.

Lowes-Hummel, P., Gertz, H-J., Ferszt, R. and CervosNavarro, J. (1989) The basal nucleus of Meynert revised: The nerve cell number decreases with age. Arch. Gerontol. Geriatrics, 8: 21-27.

Lucassen, P.J., Salehi, A., Pool, C.W., Gonatas, N.K. and Swaab, D.F. (1994) Activation of vasopressin neurons in aging and Alzheimer's disease. J. Neuroendocr., 6: 673-679. 
Lucassen, P.J., Hofman, M.A. and Swaab, D.F. (1995) Increased light intensity prevents the age related loss of vasopressin-expressing neurons in the rat suprachiasmatic nucleus. Brain Res., 693: 261-266.

Lyman, C.P., O'Brien, R.C., Greene, G.C. and Papafrangos, E.D. (1981) Hibernation and longevity in the Turkish Hamster mesocricetus brandti. Science, 212: 668-670.

Malherbe, P., Richards, J.G., Martin, J.R., Bluethmann, H., Maggio, J. and Huber, G. (1996) Lack of $\beta$-amyloidosis in transgenic mice expressing low levels of familial Alzheimer's disease missense mutations. Neurobiol. Aging, 17: 205-214.

Mann, D.M.A., Neary, D., Yates, P.O., Lincoln, J., Snowden, J.S. and Stanworth, P. (1981) Alterations in protein synthetic capability of nerve cells in Alzheimer's disease. J. Neurosurg. Psychiat., 44, 97-102.

Mann, D.M.A. and Jones, D. (1990) Deposition of amyloid (A4) protein within the brains of persons with dementing disorders other than Alzheimer's disease and Down's syndrome. Neurosci. Lett., 109: 68-75.

Mann, D.M.A., Yates, P.O. and Marcyniuk, B. (1984) Changes in nerve cells of the nucleus basalis of Meynert in Alzheimer's disease and their relationship to ageing and to the accumulation of lipofuscin pigment. Mechan. Ageing Dev., 25: 189-204.

Mann, D.M.A., Yates, P.O. and Marcyniuk, B. (1985) Some morphometric observations in the cerebral cortex and hippocampus in presenile Alzheimer's disease, Senile dementia of Alzheimer type and Down's syndrome in middle age. $J$. Neurol. Sci., 69: 139-159.

Manning, C.A., Ragozzino, M.E. and Gold, P.E. (1993) Glucose enhancement of memory in patients with probable Senile Dementia of the Alzheimer's type. Neurobiol. Aging, 14: 523-528.

Mantione, J.R., Kleppner, S.R., Miyazono, M., Wertkin, A.M., Lee, V.M.-Y. and Trojanowski, J.Q. (1995) Human neurons, that constitutively secrete $\mathrm{A} \beta$ do not induce Alzheimer's disease pathology following transplantation and long-term survival in the rodent brain. Brain Res., 671: $333-337$.

Marcus, D.L., de Leon, M.J., Goldman, J., Logan, J., Christman, D.R., Wolf, A.P., Fowler, J.S., Hunter, K., Tsai, J., Pearson, J. and Freedman, M.L. (1989) Altered glucose metabolism in microvessels from patients with Alzheimer's disease. Ann. Neurol., 26: 91-94.

Masliah, E., Sisk, A., Mallory, M., Mucke, L., Schenk, D. and Games, D. (1996) Comparison of neurodegenerative pathology in transgenic mice overexpressing V717F $\beta$-amyloid precursor protein and Alzheimer's disease. J. Neurosci., 16: 5795-5811.

Masoro, E.J., Yu, B.P. and Bertrand, H.A. (1982) Action of food restriction in delaying the aging process. Proc. Natl. Acad. Sci. USA, 79: 4239-4241.

Masters, C.L., Simms, G., Weinman, N.A., Multhaup, G., McDonald, B.L. and Beyreuther, K. (1985) Amyloid core plaque protein in Alzheimer disease and Down syndrome. Proc. Natl. Acad. Sci. USA, 82: 4245-4249.

McBee, W.L., Dailey, M.E., Dugan, E. and Shumaker, S.A. (1997) Hormone replacement therapy and other potential treatments for dementias. Menopause Horm. Replacement Ther., 26: 329-345.

McCarter, R., Masoro, E.J. and Yu, B.P. (1985) Does food restriction retard aging by reducing the metabolic rate? $\mathrm{Am}$. J. Physiol., 248: E488-E490.

McKee, A.C., Kosik, K.S. and Nowall, N.W. (1991) Neuritic pathology and dementia in Alzheimer's disease. Ann. Neurol., 30: $156-165$.

Meier-Ruge, W., Bertoni-Freddari, C. and Iwangoff, P. (1994) Changes in brain glucose metabolism as a key to the pathogenesis of Alzheimer's disease. Gerontology, 40: 246 252.

Meneilly, G.S. and Hill, A. (1993) Alterations in glucose metabolism in patients with Alzheimer's disease. J. Am. Geriatr. Soc., 41: 710-714.

Mesulam, M.M., Mufson, M.J., Levey, A.I. and Wainer, B.H. (1983) Cholinergic innervation of cortex by the basal forebrain: Cytochemistry and cortical connections of the septal area, diagonal band nuclei, nucleus basalis (substantia innominata), and hypothalamus in the rhesus monkey. $J$. Comp. Neurol., 214: 170-197

Mielke, R., Herholz, K., Grond, M., Kessler, J. and Heiss, W.D. (1994) Clinical deterioration in probable Alzheimer's disease correlates with progressive metabolic impairment of association areas. Dementia, 5: 3641.

Mielke, R., Schröder, R., Fink, G.R., Kessler, J., Herholz, K. and Heiss, W.-D. (1996) Regional cerebral glucose metabolism and postmortem pathology in Alzheimer's disease. Acta Neuropathol., 91: 174-179.

Mielke, R., Herholz, K., Grond, M., Kessler, J. and Heiss, W.D. (1994) Clinical deterioration in probable Alzheimer's disease correlates with progressive metabolic impairment of association areas. Dementia, 5: 36-41.

Miller, M.A., Urban, J.H. and Dorsa, D.M. (1989) Steroid dependency of vasopressin neurons in the bed nucleus of the stria terminalis by in situ hybridization. Endocrinology, 125: 2335-2340

Mishima, K., Okawa, M., Hishikawa, Y., Hozumi, S., Hori, H. and Takahashi, K. (1994) Morning bright light therapy for sleep and behavior disorders in elderly patients with dementia. Acta Psychiatr. Scand., 89: 1-7.

Mooradian, A.D., Chung, H.C. and Shah, G.N. (1997) GLUT1 expression in the cerebra of patients with Alzheimer's disease. Neurobiol. Aging, 18: 469-474.

Mori, E., Hirono, N., Yamashita, H., Imamura, T., Ikejiri, Y., Ikeda, M., Kitagaki, H., Shimomura, T. and Yoneda, Y. (1996) Premorbid brain size as a determinant of reserve capacity against intellectual decline in Alzheimer's disease. Am. J. Psychiatry, 154: 18-24. 
Morrison, J.H., Foote, S.L., O'Conner, D. and Bloom, F.E. (1982) Laminar, tangential and regional organization of the noradrenergic innervation of monkey cortex: Dopamine- $\beta$ hydroxylase immunohistochemistry. Brain Res. Bull., 9: 309319.

Mortel, K.F., Meyer, J.S., Herod, B. and Momby, J. (1995) Education and occupation as risk factors for dementias of the Alzheimer' and ischemic vascular types. Dementia, 6: 55-62.

Mortimer, J.A. and Graves, A.B. (1993) Education and other socioeconomic determinants of dementia and Alzheimer's disease. Neurology, 43: 539-544.

Mukaetova-Ladinska, E.B., Harrington, C.R., Roth, M. and Wischik, C.M. (1993) Biochemical and anatomical redistribution of tau protein in Alzheimer's disease. Am. J. Pathol., 143: $565-578$.

Mullan, M., Houlden, H., Windelspect, M., Fidani, L., Lombardi, C., Diaz, P., Rossor, M., Crook, R., Hardy, J., Duff, K. and Crawford, F. (1992) A locus for familial earlyonset Alzheimer's disease on the long arm of chromosome 14, proximal to the alpha 1-anti-chymotrypsin gene. Nature Genet., 2: 340-342.

Nakamura, S., Takemura, M., Ohnishi, K., Suenaga, T., Nishimura, M., Akiguchi, I., Kimura, J. and Kimura, T. (1993) Loss of large neurons and occurrence of neurofibrillary tangles in the tuberomammillary nucleus of patients with Alzheimer's disease. Neurosci. Lett., 151: 196-199.

Neve, R.L. and Robakis, N.K. (1998) Alzheimer's disease: A reexamination of the amyloid hypothesis. Trends Neurosci., 21: 15-19.

Newman, H.M., Stevens, R.T. and Apkarian, A.V. (1996) Direct spinal projections to limbic and striatal areas: Anterograde transport studies from the upper cervical spinal cord and the cervical enlargement in squirrel monkey and rat. $J$. Comp. Neurol., 365: 640-658.

Nordberg, A., Lilja, A., Lundqvist, H., Hartvig, P., Amberla, K., Viitanen, M., Jobansson, M., Hellstrom-Lindahl, E. and Bjurling, P. et al. (1992) Tacrine restores cholinergic nicotinic receptors and glucose metabolism in Alzheimer patients as visualized by positron emissiontomography. Neurobiol. Aging, 13: 747-758.

Nordberg, A. (1995) Long-term treatment with tacrine: Effects on progression of Alzheimer's disease as determined by functional brain studies. In: K. Iqbal, J.A. Mortimer, B. Winblad and H.M. Wisniewski (Eds.), Research advances in Alzheimer's disease and related disorders. John Wiley and Sons, New York, pp. 293-298.

Ohkura, T., Isse, K., Akazawa. K., Hamainoto, M., Yaoi, Y. and Hagino, N. (1994a) Low-dose estrogen replacement therapy for Alzheimer's disease in women. Menopause, 1: 125-130.

Ohkura, T., Isse, K., Akazawa, K., Hainamoto, M., Yaoi, Y. and Hagino, N. (1994b) Evaluation of estrogen treatment in female patients with dementia of the Alzheimer type. Endocrine J., 41: 361-371.
Okawa, M., Mishima, K. and Shimizu, T. et al. (1989) Sleepwake rhythm disorder and phototherapy in elderly patients with dementia. Jpn. J. Psychiatry Neurol., 43: 293-295.

Okawa, M., Mishima, K., Hishikawa, Y., Hozumi, S., Hori, H. and Takahashi, K. (1991) Circadian rhythm disorders in sleep-waking and body temperature in elderly patients with dementia and their treatment. Sleep, 14: 478-485.

Olsson, T., Mohammed, A.H., Donaldson, L.F., Henriksson, B.G. and Seckl, J.R. (1994) Glucocorticoid receptor and NGFI-A gene expression are induced in the hippocampus after environmental enrichment in adult rats. Mol. Brain Res., 23: 349-353.

Orr, W.C. and Sohal, R.S. (1994) Extension of life-span by overexpression of superoxide dismutase and catalase in Drosophila melanogaster. Science, 263: 1128-1130.

Pearson, R.C.A., Esiri, M.M., Hiorns, R.W., Wilcock, G.K. and Powell, T.P.S. (1985) Anatomical correlates of the distribution of the pathological changes in the neocortex in Alzheimer's disease. Proc. Natl. Acad. Sci. USA, 82: 4531-4534.

Pearson, R.C.A., Gatter, K.C. and Powell, T.P.S. (1983) Retrograde cell degeneration in the basal nucleus in monkey and man. Brain Res., 261: 321-326.

Peppard, R.F., Martin, W.R.W., Carr, G.D., Grochowski, E., Schulzer, M., Guttman, M., McGeer, P.L., Phillips, A.G., Tsui, J.K.C. and Calne, D.B. (1992) Cerebral glucose metabolism in Parkinson's disease with and without dementia. Arch. Neurol., 49: 1262-1268.

Pericak-Vance, M.A., Bebout, J.L., Gaskell, Jr, P.C., Yamaoka, L.H., Hung, W.Y., Alberts, M.J., Walker, A.P., Bartlett, R.J., Haynes, C.A., Welsh, K.A., Earl, N.L., Heyman, A, Clark, C.M. and Roses, A.D. (1991) Linkage studies in familial Alzheimer disease: Evidence for chromosome 19 linkage. Am. J. Human Genet., 48: 1034-1050.

Powell, R.R. (1974) Psychological effects of exercise therapy upon institutionalized geriatric mental patients. J. Terato$\log y, 29:$ 157-164.

Powell, R.R. (1974) Psychological effects of exercise therapy in institutionalized geriatric mental patients. J. Gerontol., 29: 157-164.

Price, J.L., Davis, P.B., Morris, J.C. and White, D.L. (1991) The distribution of tangles, plaques and related immunohistochemical markers in healthy aging and Alzheimer's disease. Neurobiol. Aging, 12: 295-312.

Quon, D., Wang, Y., Catalano, R., Scardina, J.M., Murakami, K. and Cordell, B. (1991) Formation of $\beta$-amyloid protein deposits in brains of transgenic mice. Nature, 352: 239-241.

Rance, N.E., McMullen, N.T., Smialek, J.E., Price, D.L. and Scott Young III, W. (1990) Postmenopausal hypertrophy of neurons expressing the estrogen receptor gene in the human hypothalamus. J. Clin. Endocrinol. Metabol., 71: 79-85.

Rance, N.E., Uswandi, S.V. and McMullen, N.T. (1993) Neuronal hypertrophy in the hypothalamus of older men. Neurobiol. Aging, 14: 337-342. 
Rance, N.E. and Young, W.S., III (1991) Hypertrophy and increased gene expression of neurons containing neurokinin $\mathrm{B}$ and substance P messengerRNAs in the hypothalamus of postmenopausal women. Endocrinology, 128: 2239-2247.

Rance, N.E. (1992) Hormonal influences on morphology and neuropeptide gene expression in the infundibular nucleus of post-menopausal women. In: D.F. Swaab, M.A. Hofman, M. Mirmiran, R. Ravid and F.W. van Leeuwen (Eds.), Progress in Brain Research, Elsevier Science Publishers, Amsterdam, pp. 221-235.

Ravid, R., Fliers. E., Swaab, D.F. and Zurcher, C. (1987) Changes in vasopressin and testosterone in the senescent Brown-Norway (BN/BiRij) rat. Gerontology, 33: 87-98.

Regeur, L., Jensen, G.B., Pakkenberg, H., Evans, S.M. and Pakkenberg, B. (1994) No global neocortical nerve cell loss in brains from senile dementia of Alzheimer's type. Neurobiol. Aging, 15: 347-352.

Reiman, E.M., Caselli, R.J., Yun, L.S., Chen, K., Bandy, D., Minoshima, S., Thibodeau, S.N. and Osborne, D. (1996) Preclinical evidence of Alzheimer's disease in persons homozygous for the $\varepsilon 4$ allele for apolipoprotein. E. N. Engl. J. Med., 334: 752-758.

Riekkinen Jr, P., Soininen, H., Helkala, E.-L., Partanen, K., Laakso, M.P., VanHanen, M. and Riekkinen Sr, P.J. (1995) Hippocampal atrophy, acute THA treatment and memory in Alzheimer's disease. Neuroreport, 6: 1297-1300.

Rinne, J.O., Paljarvi, L. and Rinne, U.K. (1987) Neuronal size and density in the nucleus basalis of Meynert in Alzheimer's disease. J. Neurol. Sci., 79: 67-76.

Roberts, G.W., Allsop, D. and Bruton, C.J. (1990) The occult aftermath of boxing. J. Neurol. Neurosurg. Psychiatr., 24: 173-182.

Robinson, D., Friedman, L., Marcus, R., Tinklenberg, J. and Yesavage, J. (1994) Estrogen replacement therapy and memory in older women. J. Am. Geriatr. Soc., 42: 919-922.

Rogers, J. and Morrison, J.H. (1985) Quantitative morphology and regional and laminar distributions of senile plaques in Alzheimer's disease. J. Neurosci., 5: 2801-2808.

Rosen, G. (1961) Gross cultural and historical approaches. In: P.H. Hoch and J. Zubin (Eds.), Psychopathology of ageing, Grune and Stratton, New York, pp. 1-20.

Rossor, M.N. (1993) Molecular pathology of Alzheimer's disease. J. Neurol. Neurosurg. Psychiatr., 56: 583-586.

Rozemuller, J.M., Eikelenboom, P., Stam, F.C., Beyreuther, K. and Masters, C.L. (1989) A4 protein in Alzheimer's disease; Primary and secondary cellular events in extracellular amyloid deposition. J. Neuropath. Exp. Neurol., 48: 674-691.

Rudelli, R.D., Ambler, M.W. and Wisniewski, H.M. (1984) Morphology and distribution of Alzheimer neuritic (senile) and amyloid plaques in striatum and diencephalon. Acta Neuropathol. (Berl), 64: 273-281.

Sajdel-Sulkowska, E.M. and Marotta, C.A. (1984) Alzheimer's disease brain: Alterations in RNA levels and in a ribonuclease-inhibitor complex. Science, 225: 947-949.
Salehi, A., Lucassen, P.J., Pool, C.W., Gonatas, N.K., Ravid, R. and Swaab, D.F. (1994) Decreased neuronal activity in the nucleus basalis of Alzheimer's disease as suggested by the size of the Golgi apparatus. Neuroscience, 59: 871-880.

Salehi, A., Van de Nes, J.A.P., Hofman, M.A., Gonatas, N.K. and Swaab, D.F. (1995a) Early cytoskeletal changes as shown by Alz-50 are not accompanied by decreased neuronal activity. Brain Res., 678: 29-39.

Salehi, A., Ravid, R., Gonatas, N.K. and Swaab, D.F. (1995b) Decreased activity of hippocampal neurons in Alzheimer's disease is not related to the presence of neurofibrillary tangles. J. Neuropathol. Exp. Neurol., 54: 704-709.

Salehi, A., Heyn, S., Gonatas, N.K. and Swaab, D.F. (1995c) Decreased protein synthetic activity of the hypothalamic tuberomammillary nucleus in Alzheimer's disease as suggested by a smaller Golgi apparatus. Neurosci. Lett., 193: 29-32.

Salehi, A., Pool, C.W., Mulder, M., Ravid, R., Gonatas, N.K. and Swaab, D.F. (1998a) Limited effect of neuritic plaques on neuronal density in the hippocampal CAI area of Alzheimer patients. Alzh. Dis. Assoc. Dis. 12: 77-82.

Salehi, A., Dubelaar, E.J.G., Mulder, M. and Swaab, D.F. (1998b) Aggravated decrease in the activity of nucleus basalis neurons in Alzheimer's disease is apolipoprotein E-type dependent. Proc. Natl. Acad. Sci. USA, 95 in press.

Salmon, E., Gregoire, M.C., Delfiore, G., Lemaire, C., Degueldre, C., Franck, G. and Comar, D. (1996) Combined study of cerebral glucose metabolism and $\left[{ }^{11} \mathrm{C}\right]$ methionine accumulation in probable Alzheimer's disease using positron emission tomography. J. Cerebr. Blood Flow Metab., 16: 399-408.

Sapolsky, R.M., Krey, L.C. and McEwen, B.S. (1986) The neuroendocrinology of stress and aging: the glucocorticoid cascade hypothesis. Endocr. Rev., 7: 284-301.

Satlin, A., Volicer, L., Ross, V., Herz, L. and Campbell, S. (1992) Bright light treatment of behavioral and sleep disturbances in patients with Alzheimer's disease. Am. J. Psychiatr., 149: 1028-1032.

Schellenberg, G.D., Bird, T.D., Wijsman, E.M., Orr, H.T., Anderson, L., Nemens, E., White, J.A., Bonnycastle, L., Weber, J.L., Alonso, M.E., Potter, H., Heston, L.L. and Martin, G.M. (1992) Genetic linkage evidence for a familial Alzheimer's disease locus on chromosome 14. Science, 258: 668-671.

Scherder, E., Bouma, A., Steen, L. and Swaab, D. (1995a) Peripheral nerve stimulation in Alzheimer's disease. A metaanalysis. Alz. Res., 1: 183-184.

Scherder, E.J.A., Bouma, A. and Steen, A.M. (1995b) Effects of short-term transcutaneous electrical nerve stimulation on memory and affective behaviour in patients with probable Alzheimer's disease. Behav. Brain Res., 67: 211-219.

Scherder, E.J.A., Bouma, A and Steen, A.M. (1995c) Effects of simultaneously applied short-term transcutaneous electrical nerve stimulation and tactile stimulation on memory and 
affective behaviour of patients with probable Alzheimer's disease. Behav. Neurol., 8: 3-13.

Scherder, E.J.A., Bouma, A. and Steen, A.M. (1992) Influence of transcutaneous electrical nerve stimulation on memory in patients with dementia of the Alzheimer type. J. Clin. Exp. Neuropsychol., 14: 951-960.

Scherder, E.J.A., Bouma, A. and Steen, A.M. (1996) Effects of a follow-up treatment of short-term transcutaneous electrical nerve stimulation on memory and affective behaviour in a patient with probable Alzheimer's disease. Behav. Neurol., 9: 33-35.

Scherder, E.J.A., Bouma, A. and Steen, A.M. (1998) "Isolated" transcutaneous electrical nerve stimulation in Alzheimer's disease. Biol. Psych. 43: 417-424.

Schofield, P.W., Mosesson, R.E.. Stem, Y. and Mayeux, R. (1995) The age at onset of Alzheimer's disease and an intracranial area measurement. Arch. Neurol., 52: 95-98.

Schofield, P.W., Logroscino, G., Andrews, H.F., Albert, S. and Stern, Y. (1997) An association between head circumference and Alzheimer's disease in a population-based study of aging and dementia. Neurology, 49: 30-37.

Schultz, C., Braak, H. and Braak, E. (1996) A sex difference in neurodegeneration of the human hypothalamus. Neurosci. Lẹtt., 212: 103-106.

Schultz, C., Ghebremedhin, E., Braak, H. and Braak, E. (1997) Neurofibrillary pathology in the human paraventricular and supraoptic nuclei. Acta Neuropathol., 94: 99-102.

Selkoe, D.J. (1994) Alzheimer's disease: A central role for amyloid. J. Neuropathol. Exp. Neurol. 53: 438- 447.

Sherwin, B.B. (1988) Estrogen and/or androgen replacement therapy and cognitive functioning in surgically menopausal women. Psychoneuroendocrinology, 13: 345-357.

Simonian, N.A. and Hyman, B.T. (1993) Functional alterations in Alzheimer's disease: Diminution cytochrome oxidase in the hippocampal formation. J. Neuropathol. Exp. Neurol., 52: 580-585.

Simonian, N.A. and Hyman, B.T. (1994) Functional alterations in Alzheimer's disease: Selective mitochondrial-encoded cytochrome oxidase mRNA in the formation. J. Neuropathol. Exp. Neurol., 53: 508-512.

Simpson, I.A., Chundu, K.R., Davies-Hill, T., Honer, W.G. and Davies, P. (1994) Decreased concentrations of GLUT1 and GLUT3 glucose transporters in the brains of patients with Alzheimer's disease. Ann. Neurol., 35: 546-551.

Slansky, I., Herholz, K., PietrLyk, U., Kessler, I., Grond, M., Mielke, R. and Heiss, W.D. (1995) Cognitive impairment in Alzheimer's disease correlates with ventricular width and atrophy-corrected cortical glucose metabolism. Neuroradiol., 37: $270-277$.

Small, G.W., Mazziotta, J.C., Collins, M.T., Baxter, L.R., Phelps, M.E., Mandelkern, M.A., Kaplan, A., La Rue, A., Adamson, C.F., Chang, L., Guze, B.H., Corder, E.H., Saunders, A.M., Haines, J.L., Pericak-Vance, M.A. and Roses, A.D. (1995) Apolipoprotein E type 4 allele and cerebral glucose metabolism in relatives at risk for familial Alzheimer disease. JAMA, 273: 942-947.

St George-Hyslop, P.H., Haines, J., Rogaev, Mortilla, M., Vaula, G., Pericak-Vance, M., Foncin, J-F., Montesi, M., Bruni, A., Sorbi, S., Rainero, I., Pinessi, L., Pollen, D., Polinsky, R., Nee, L., Kennedy. J., Macciardi, Rogaeva, E., Liang, Y., Alexandrova, N., Lukiw, W., Schlumpf, K., Tanzi, R., Tsuda, T., Farrer, L., Cantu, J-M., Duara, R., Amaducci, L., Bergamini, L., Gusella, Roses, A. and Crapper McLachlan, D. (1992) Genetic evidence for a novel familial Alzheimer's disease locus on chromosome 14. Nature Genet., 2: 330-334.

Standaert, D.G., Lee, V.M-Y., Greenberg, B.D., Lowery, D.E., Trojanowski, J.Q. (1991) Molecular features of hypothalamic plaques in Alzheimer's disease. Am. J. Pathol., 139: 681-691.

Stephenson, J. (1996) More evidence links NSAID 1 estrogen use with reduced Alzheimer risk. JAMA, 275: 1389-1390.

Stern, Y., Guriand, B. and Tatemichi, T. et al. (1994) Influence of education and occupation on the incidence of Alzheimer's disease. JAMA, 271:1004-1010.

Stern, Y., Tang, M.X., Denaro, J. and Mayeux, R. (1995) Increased risk of mortality in Alzheimer's disease patients with more advanced educational and occupational attainment. Ann. Neurol., 37: 590-595.

Strittmatter, W.J., Saunders, A.M., Schmechel, D., PericakVance, M., Enghild, J., Salvesen, G.S. and Roses, A.D. (1993a) Apolipoprotein E: High-avidity binding to $\beta$-amyloid and increased frequency of type allele in late-onset familial Alzheimer disease. Proc. Natl. Acad. Sci. USA, 90: 1977-1981.

Strittmatter, W.J., Weisgraber, K.H., Huang, D.Y., Dong, LM., Salvesen, G.S., Pericak-Vance, M., Schmechel, D., Saunders, A.M., Goldgaber, D. and Roses, A.D. (1993b) Binding of human apolipoprotein $\mathrm{E}$ to synthetic amyloid beta peptide; isoform specific effects and implications for late-onset Alzheimer disease. Proc. Natl. Acad. Sci. USA, 90 : 8098-8102.

Sturchler-Pierrat, C., Abramowski, D., Duke, M., Wiederhold, K.-H., Mistl, C., Rothacher, S., Ledermann, B., Bürki, K., Frey, P., Paganetti, P.A., Waridel, C., Calhoun, M.E., Jucker, M., Probst, A., Staufenbiel, M. and Sommer, B. (1997) Two amyloid precursor protein transgenic mouse models with Alzheimer disease-like pathology. Proc. Natl. Acad. Sci. USA 94: 13287-13292.

Sumi, S.M., Bird, T.D., Nochlin, D. and Raskind, M.A. (1992) Familial presenile dementia with psychosis associated with cortical neurofibrillary tangles and degeneration of the amygdala. Neurology, 42: 120-127.

Suzuki, K., Katzman, R. and Korey, S.R. (1965) Chemical studies on Alzheimer's disease. J. Neuropathol. Exp. Neurol., 24: 211-224.

Swaab, D.F., Fliers, E. and Partiman, T (1985) The suprachiasmatic nucleus of the human brain in relation to sex, age and dementia. Brain Res., 342: 37-44. 
Swaab, D.F. and Hofman, M.A. (1988) Sexual differentiation of the human hypothalamus: ontogeny of the sexually dimorphic nucleus of the preoptic area. Dev. Brain Res., 44: 314-318.

Swaab, D.F. (1991) Brain aging and Alzheimer's disease: "wear and tear" versus "use it or lose it". Neurobiol. Aging, 12: 317324.

Swaab, D.F., Grundke-Iqbal, I., Iqbal, K., Kremer, H.P.H., Ravid, R. and Van de Nes, J.A.P. (1992) Tau and ubiquitin in the human hypothalamus in aging and Alzheimer's disease. Brain Res., 590: 239-249.

Swaab, D.F. (1997) Neurobiology and neuropathology of the human hypothalamus. In: F.E. Bloom, A. Björklund, T. Hökfelt (Eds.) Handbook of Chemical Neuroanatomy 13: The Primate Nervous System, Part 1. Elsevier, Amsterdam.

Swerdlow, R., Marcus, D.L., Landman, J., Kooby, D., Frey, W. and Freedman, M.L. (1994) Brain glucose metabolism in Alzheimer's disease. Am. J. Med. Sci., 308: 141-144.

Tagliavini, F., Giaccone, G., Verga, L., Ghiso, J., Frangione, B. and Bugiani, O. (1991) Alzheimer patients: Preamyloid deposits are immunoreactive with antibodies to extracellular domains of the amyloid precursor protein. Neurosci. Lett., 128: 117-120.

Tang, M.X., Jacobs, D., Stern, Y., Marder, K., Schofield, P., Surland, B., Andrews, M. and Mayeux, R. (1996) Effect of oestrogen during menopause on risk and age of onset of Alzheimer's disease. Lancet, 348: 429-432.

Tate, B., Aboody-Guterman, K.S., Morris, A.M., Walcott, E.C., Majocha, R.E. and Marotta, C.A. (1992) Disruption of circadian regulation by brain grafts that overexpresses Alzheimer $\beta / A 4$ amyloid. Proc. Natl. Acad. Sci. USA, 89: 7090-7094.

Taylor, G.R., Carter, G.I., Crow, T.J., Johnson, J.A. and Fairbairn, A.F. (1986) Recovery and measurement of specific RNA species from tissue: a general reduction in Alzheimer's disease detected by hybridization. Exp. Mol. Pathol., 44: 111-116.

Te Koppele, J.M., Lucassen, P.J., Sakkee, A.N., Van Asten, J.G., Ravid, R., Swaab, D.F. and Van Bezooijen, F.A. (1996) $80 \mathrm{HdG}$ levels in brain do not indicate oxidative DNA damage in Alzheimer's disease. Neurobiol. Aging, 17: 819826.

Terry, R.D., Hansen, L.A., DeTeresa, R., Davies, P., Tobias, H. and Katzman, R. (1987) Senile dementia of the Alzheimer type without neocortical neurfibrillary tangles. J. Neuropath. Exp. Neurol., 46: 262-268.

Torack, R.M. and Miller, J.W. (1995) Denervation induced abnormal phosphorylation in hippocampal neurons. Brain Res., 669: 135-139.

Ule, G., Schwechheimer, K. and Tsachhargane, C. (1983) Morphological feedback effects on neurons of the nucleus arcuatus (sive infundibularis) and nucleus subventricularis hypothalami due to gonadal atrophy. Virchovs. Arch. [A], 400: 297-308.
Van Broeckhoven, C., Backhovens, H., Cruts, M., De Winter, G., Bruyland, M., Cras, P. and Martin, J-J. (1992) Mapping of a gene predisposing to early - onset Alzheimer's disease to chromosome 14q24.3. Nature Genet., 2: 335-339.

Van de Nes, J.A.P., Kamphorst, W., Ravid, R. and Swaab, D.F. (1993) The distribution of Alz-50 immunoreactivity in the hypothalamus and adjoining areas of Alzheimer's disease patients. Brain, 116: 103-115.

Van de Nes, J.A.P., Kamphorst, W. and Swaab, D.F. (1994) Arguments for and against the primary amyloid local induction hypothesis of the pathogenesis of Alzheimer's disease. Ann. Psychiat., 4: 95-111.

Van de Nes, J.A.P., Kamphorst, W., Ravid, R. and Swaab, D.F. (1998) Comparison of $\beta$-protein/A4 deposits and Alz-50 stained cytoskeletal changes in the hypothalamus and adjoining areas of Alzheimer's disease patients: Amorphic plaques and cytoskeletal changes occur independently. Acta Neuropathol. 96, 129-138.

Van der Woude, P.F., Goudsmit, E., Wierda, M., Purba, J.S., Hofman, M.A., Bogte, H. and Swaab, D.F. (1995) No vasopressin cell loss in the human paraventricular and supraoptic nucleus during aging and in Alzheimer's disease. Neurobiol. Aging, 16: 11-18.

Van Gool, W.A., Pronker, H.F., Mirmiran, M. and Uylings, H.B.M. (1987) Effect of housing in an enriched environment on the size of the cerebral cortex in young and old rats. Exp. Neurol., 96: 225-232.

Van Someren, E.J.W., Mirmiran, M. and Swaab, D.F. (1993) Non-pharmacological treatment of sleep and wake disturbances in aging and Alzheimer'sdisease: Chronobiological perspectives. Behav. Brain Res., 57: 235-253.

Van Someren, E.J.W., Hagebeuk, E.E.O., Lijzenga, C., Scheltens, P., De Rooij, S.E.J.A., Jonker, C., Pot, A.M., Mirmiran, M. and Swaab, D.F. (1996) Circadian rest-activity rhythm disturbances in Alzheimer's disease. Biol. Psych., 40: 259-270.

Van Someren, E.J.W. (1997) Rest-activity rhythms in aging, Alzheimer's disease and Parkinson's disease. Ph.D.-thesis, July 1997, Amsterdam.

Van Someren, E.J.W., Kessler, A., Mirmiran, M. and Swaab, D.F. (1997a) Indirect bright light improves circadian restactivity rhythm disturbances in demented patients. Biol. Psych., 41: 955-963.

Van Someren, E.J.W., Lijzenga, C., Mirmiran, M. and Swaab, D.F. (1997b) Long-term fitness training improves the circadian rest-activity rhythm in healthy elderly males. J. Biol. Rhythms, 12: 146-156.

Van Someren, E.J.W., Scherder, E.J.A. and Swaab, D.F. (1998) Transcutaneous electrical nerve stimulation (TENS) improves circadian rhythm disturbances in Alzheimer's disease. Alzheimer Dis. Assoc. Disord. 12, 114-118.

Verwer, R.W.H., Jansen, K.A., Sluiter, A.A., Pool, C.W. and Swaab, D.F. (1998) Decreased hippocampal metabolic activity in Alzheimer patients is not reflected in the immunoreactivity of cytochrome oxidase subunits. (submitted). 
Vogels, O.J.M., Broere, C.A.J., Ter Laak, H.J., Ten Donkelaar, H.J., Nieuwenhuys, R. and Schulte, B.P.M. (1990) Cell loss and shrinkage in the nucleus basalis Meynert complex in Alzheimer's disease. Neurobiol. Aging, 11: 3-13.

Wallace, D.C. (1992) Mitochondrial genetics: A paradigm for aging and degenerative diseases? Science, 256: 628-632.

Wallace, C.S., Withers, G.S., Weiler, I.J., George, J.M., Clayton, D.F. and Greenough, W.T. (1995) Correspondence between sites of NGFI-A induction and sites of morphological plasticity following exposure to environmental complexity. Mol. Brain Res., 32: 211-220.

West, M.J., Coleman, P.D., Flood, D.G. and Tronsoco, J.C. (1994) Differences in the pattern of hippocampal neuronal loss in normal ageing and Alzheimer's disease. Lancet, 344: 769-772.

Whitehouse, P.J., Price, D.L., Struble, R.G., Clark, A.W., Coyle, J.T. and Delong, M.R. (1982) Alzheimer's disease and senile dementia: Loss of neurons in the basal forebrain. Science, 215: 1237-1239.

Whitehouse, P.J., Hedreen, J.C., White, C.L., Clark, A.W. and Price, D.L. (1983) Neuronal loss in the basal forebrain cholinergic system is more marked in Alzheimer's disease than in senile dementia of the Alzheimer type. Ann. Neurol., 14: 149 .

Widerlöv, E., Bråne, G., Ekman, R., Kihlgren, M., Norberg, A. and Karlsson, I. (1989) Elevated CSF somatostatin concentrations in demented patients parallel improved psychomotor functions induced by integrity-promoting care. Acta Psychiatr. Scand., 79: 41-47.

Wirak, D.O., Bayney, R., Ramabhadran, T.V., Fracasso, R.P., Hart, J.T., Hauer, P.E., Hsiau, P., Pekar, S.K., Scangos, G.A., Trapp, B.D. and Unterbeck, A.J. (1991) Deposits of amyloid protein in the central nervous system of transgenic mice. Science, 253: 1-2.

Wisniewski, H.M. and Wegiel, J. (1995) The neuropathology of Alzheimer's disease. Neuroimaging Clin. N. Am., 5: 45-57.

Witting, W., Mirmiran, M., Bos, N.P. and Swaab, D.F. (1993) Effect of light intensity on diurnal sleep-wake distribution in young and old rats. Brain Res. Bull., 30: 157-162.

Witting, W., Kwa, I.H., Eikelenboom, P., Mirmiran, M. and Swaab, D.F. (1990) Alterations in the circadian rest-activity rhythm in aging and Alzheimer's disease. Biol. Psychiatr., 27 : $563-572$.

Wong-Riley, M.T.T. (1989) Cytochrome oxydase: An endogenous metabolic marker for neuronal activity. Trends in Neurosci., 12: 94-101.

Woods, R.T. (1979) Reality orientation and staff attention: a controlled study. Brit. J. Psych., 134: 502-507.

Zanetti, O., Frisoni, G.B., De Leo, D., Della Buono, M., Bianchetti, A. and Trabucchi, M. (1995) Alzh. Dis. Rel. Dis., 9: $132-138$.

Yankner, B.A. (1992) Commentary and perspective on studies of beta amyloid neurotoxicity. Neurobiol. Aging, 13: 615616. 